\title{
Artículos
}

\section{Análisis de coyuntura económica Segundo semestre de 1999}

\author{
Departamento de Economía \\ de la Universidad Centroamericana "José Simeón Cañas"
}

\begin{abstract}
Resumen
El Salvador se encuentra en un período de crecimiento cercano a cero. Al finalizar 1999 se concluye que la economfa se encamina hacia el estancamiento: altos niveles de desempleo, el estancamiento por una década de los salarios mínimos reales, el lento crecimiento de los salarios reales promedio y la concentración del ingreso - en que el 20 por ciento de las familias más pobres reciben apenas el 5.7 por ciento del ingreso-. Todo ello se traduce en cientos de miles de personas que viven en condiciones de pobreza y extrema pobreza.
\end{abstract}

\section{Introducción'}

En el análisis de coyunturą económica del segundo semestre de 1999 se hace un esfuerzo por presentar la evolución de los principales agregados económicos a partir de su comportamiento durante la década de los noventa. En tal sentido, la coyuntura se interpreta como el resultado acumulado de lo acontecido en años anteriores, junto con los acontecimientos particulares del último semestre.

Al finalizar 1999 se concluye que la economía se encamina hacia el estancamiento. En el umbral de un nuevo siglo, El Salvador se encuentra en un período de crecimiento cercano a cero, y la econo- mía no logra despegar. Esto significa que el país ya no puede incrementar las tasas de crecimiento que se necesitan tan urgentemente para reducir la pobreza y entrar a una etapa de desarrollo sostenible, sin que se hagan importantes transformaciones en la estructura de relaciones económicas y sociales. En 1999, el producto interno bruto (PIB) creció 2.2 por ciento y el PIB per cápita 0.1 por ciento. En promedio, en el período 1992-1999, el PIB per cápita creció 2.7 por ciento al año, y el crecimiento se concentró en la primera mitad de la década y se mantuvo muy débil en la segunda (Gráfica 1).

Respecto a la evolución sectorial de la economía, se evidencia que el sector que más creció —es decir, el que impulsó el escaso crecimiento que se

1. Informe elaborado por Álvaro Trigueros (secciones 1, 4, 6 y 7), Lilian Vega (secciones 2 y 3) y Francisco Lazo Marín (sección 5). El documento también se enriqueció con las sugerencias de Francisco Javier Ibisate, Sara González, Mario Montesino, Aquiles Montoya y Gerardo Olano. 
logró este año-, fue el sector industrial, que a su vez cada año crece más despacio. El índice de volumen de la producción industrial creció 5 por ciento en su promedio móvil al mes de noviembre, en comparación con el 8.9 por ciento que aumentó en 1998. En segundo lugar se encuentra la agricultura - cuyo crecimiento se estima en 3.7 por ciento anual-, lo cual responde más a condiciones climatológicas que a una reactivación del sector, mismo que ha mostrado señales claras de estancamiento a lo largo de la década. El resto de sectores no ha mostrado un crecimiento ejemplar durante 1999, lo que deja a la economía sin un eje de acumulación, en torno al cual crecerían los demás sectores.

Por su parte, la evolución del empleo refleja el comportamiento de los sectores produclivos y un deterioro en la calidad de vida de los salvadoreños. La tasa de desempleo abierta llegaba a 6.5 por ciento en noviembre de 1999, y la tasa de subempleo alcanzó un promedio de 32.2 por ciento en 1999. Así mismo, la evolución de los últimos seis meses - visto desde el punto de vista de la tasa de desempleo o del número de cotizantes activos en el sistema privado de pensiones-, muestra un deterioro de la situación laboral. Apenas dos tercios de la población económicamente activa se encuentra plenamente ocupada, mientras que aproximadamente un tercio de la misma se ve sometida al flagelo del desempleo o el subempleo, donde la calidad y la remuneración del trabajo no permiten satisfacer las necesidades más elementales.

Similarmente, la evolución de los macro precios apunta a un estancamiento en la demanda agregada. Por un lado, la inflación anual, a partir del índice de precios al consumidor, fue de -1 por ciento al mes de diciembre de 1999. El fuerte incremento en los precios del petróleo, a lo largo de 1999, comienza a dar señales de presión sobre los precios de los productos industriales, lo que puede incidir posteriormente en una mayor inflación para el año 2000.

Por el lado de los salarios reales, si bien el salario promedio real -medido a partir del ingreso básico cotizable de las Asociaciones de Fondos para Pensiones- mostró un crecimiento del 14 por ciento con respecto a 1990 , este último año sólo creció 0.7 por ciento, mientras que los salarios mínimos permanecieron práclicamente estancados en el nivel de 1990. Más aún, cabe recordar que tradicionalmente la distribución del ingreso en
El Salvador refleja un modelo excluyente. Según la Encuesta de Hogares y Propósitos Múltiples de 1998, el 20 por ciento de las familias más pobres recibe el 5.7 por ciento del ingreso, mientras que el 20 por ciento de los hogares más ricos reciben el 48 por ciento de los ingresos. Ambos factores, unidos al fenómeno del subempleo y desempleo, constituyen una razón suficiente para pensar en una demanda de consumo deprimida, aunada al problema del crecimiento económico mencionado anteriormente.

Adicionalmente, tasas de interés activas reales que llegaron a 16.3 por ciento en diciembre de 1999, junto con las comisiones por las transacciones financieras, implicaron un elevado costo para las empresas, lo que produjo una disminución en la demanda por inversión y vivienda. Finalmente, el deterioro en el tipo de cambio efectivo rcal, es decir la apreciación de la moneda en más del 50 por ciento a lo largo de la década, resultado del. flujo de divisas, conllevó a un mayor crecimiento en las importaciones, lo cual contribuyó al desequilibrio externo de nuestra economía.

En cuanto a los agregados monetarios, se encuentran indicios claros de una política monetaria restrictiva; además, existe un esfuerzo deliberado por conducir la economía hacia un esquema de caja de convertibilidad o de dolarización. Los datos que sustentan este argumento son: (a) la reducción en el crecimiento de la oferta monetaria M2 y M3, que crecieron 6.4 y 7.3 por ciento, respectivamente, en 1999, en comparación con las tasas de crecimiento por encima del 20 por ciento en la primera mitad de la década; $(b)$ el alza en el encaje legal, que prevaleció a lo largo de casi todo el año, ya que apenas el 24 de noviembre de 1999 regresó a su nivel inicial de noviembre de 1998; (c) la compra neta de dólares por parte del Banco Central de Reserva, que ha conllevado a tal aumento de los activos externos netos de la Base Monetaria -que representan el cien por ciento de aquella - y de las Reservas Internacionales Netas (RIN), que en noviembre llegaban a representar un 118.6 por ciento de la Base Monetaria, y 6.9 meses de importaciones; $(d)$ la política de esterilización del BCR, de tal manera que la emisión de títulos valores llegó a 6,340.8 millones de colones en noviembre de 1999, en comparación con los 2,890 millones en diciembre de 1996. Estos hechos ayudan a explicar, en parte, la existencia de tasas de interés reales elevadas. También es de la- 
mentar que los esfuerzos de esterilización del Banco Central de Reserva conducen a la desviación de fondos fínancieros que podrían estar destinados a la inversión productiva. En noviembre, $495.9 \mathrm{mi}-$ llones de colones de las Asociaciones de Fondos para Pensiones, 353.6 millones de los bancos comerciales y 3,937.1 millones de la bolsa de valores estaban invertidos en títulos valores emitidos por el Banco Central de Reserva.

El sector bancario ha mostrado una tendencia hacia la concentración del mercado, reforzando su cstructura de competencia monopolística. Así se liene que, con las fusiones recientes de Bancorp y el Banco Capital, y la del Banco de Comercio con Atlacatl, el índice de concentración IHH subió de 1,274.5 - que había en marzo de 1997- a 1353.0, en septiembre de 1999, y de materializarse la fusión entre el Banco Desarrollo y el Banco Agrícola Comercial, este índice subiría a 1,738.2 en el año 2000. Es de deslacar que la entrada de capitales extranjeros, como el Hamilton Bank en el Unibanco, o el Scotiabank en Ahorromet, y la presencia de accionistas extranjeros en otros bancos, no ha logrado revertir esa tendencia hacia la concentración bancaria. Si bien hay varios factores que explican el mantenimiento de altas lasas de interés — como se mencionó en el párrafo anterior-, la estructura de competencia monopolística de los bancos no se puede pasar por alto como posible factor explicativo. En tal sentido, aunado a las altas comisiones que cobran los bancos por algunas de las transacciones linancicras, el sector puede convertirse en un generador de estancamiento y, en lugar de ser un apoyo para impulsar el crecimiento, podría constituirse en un obstáculo más por enfrentar.

En el segundo semestre de 1999 continuó el dclcrioro de la cartera de los bancos, al aumentar la mora bancaria hasta un 7.33 por ciento de los préstamos brutos, mientras que hasta septiembre el crecimiento de los depósitos y de los activos totales -5.66 y 5.52 por ciento, respectivamentefue mucho más bajo que el obtenido en 1997 y 1998. Io cual refleja la difícil situación en el que se encuentra el rubro económico. En el mes de scptiembre se aprobó la nueva Ley de Bancos, la cual hace más estricta la supervisión y los requeri- mientos de funcionamiento de los bancos, con el objetivo de lograr estabilidad en el sistema financiero; sin embargo, además de una legislación adecuada se necesitan instituciones fuertes que la hagan efectiva. La Superitendencia del Sistema Financiero, el Instituto de Garantía para los Depósitos y el Banco Central de Reserva deberán demostrar que logran este objetivo plasmado en la ley.

A más de un año de la instauración del nuevo sistema de pensiones, el valor nominal de los fondos llegaba a 1,835 millones de colones en diciembre de 1999, representando aproximadamente un 1.8 por ciento del PIB. Esto ha llevado a las Asociaciones de Fondos para Pensiones a saturar el mercado de valores, en el sentido de que éstas casi no encuentran opciones de inversión. En oclubre, el 97.8 por ciento de los fondos de pensiones estaban invertidos en instrumentos de renta fija, la mayoría en instrumentos públicos -incluyendo los títulos valores emitidos por el Banco Central de Reserva, y las emisiones de los bancos-, mientras que apenas un 2.2 por ciento correspondía a instrumentos de renta variable, casi en su totalidad perteneciente a la empresa Telefónica. Por otra parte, las Asociaciones de Fondos para Pensiones representaban el 48.4 por ciento del mercado secundario de la bolsa de valores.

Las finanzas públicas continúan siendo el talón de Aquiles de los últimos años. El défícit fiscal alcanzó un 3 por ciento del PIB en 1999, la proporción más alta desde 1993. Esto se explica por la evolución asimétrica que existe entre los gastos y los impuestos. Mientras los gastos han aumentado su participación sobre el PIB, de 12.82 por ciento en 1997 a 13.99 por ciento en 1999 , la carga tributaria se mantiene estancada por debajo del 11 por ciento, llegando apenas al 10.78 por ciento en 1999. Para el año 2000 se ha proyectado una meta de déficit fiscal de 2.6 por ciento del PIB, el cual se sustenta en una incremento en la recaudación tributaria a 12.6 por ciento del PIB, lo cual no se considera factible dada la evolución de los últimos años. Adicionalmente, la reforma de pensiones implica un incremento en el gasto público de 452 millones de colones en el año 2000. Por supuesto, cabe esperar en cada año subsiguiente 
incrementos adicionales mayores, para lo cual el gobierno no ha explicado cómo va enfrentar dicho problema, a pesar de ser una situación perfectamente previsible.

Continuando con la política fiscal, por primera vez en tres años el año 2000 comienza con un presupuesto aprobado. Consistente con la evolución de años anteriores, el gasto en Desarrollo Social aumentará su participación a 37.2 por ciento del total de los gastos por área de gestión, comparado con el 32.I por ciento que hubo en 1997. Sin cmbargo, el gasto en Apoyo al Desarrollo Económico reduce su participación de 14.4 por ciento que tuvo en 1997, a 10.6 por ciento en el año 2000. Si bien el incremento del Gasto en DesarroIlo Social -que incluye gastos en educación y salud-es muy positivo para el desarrollo nacional, se cuestiona la reducción del gasto en Apoyo al Desarrollo Económico, al no dejar clara cuál es la intención del gobierno. Ante las urgentes necesidades sociales del país, y la paz alcanzada a nivel centroamericano, no se entiende por qué el Ramo de la Defensa Nacional todavía absorberá el 5.2 por ciento del presupuesto nacional -es decir, 950.3 millones de colones-, cuando ya el Ramo de Seguridad y Justicia tiene asignados 1,468.4 millones de colones.

En cuanto al sector externo, a pesar de la solvencia de la que goza el país, el sector sigue mosrando serias debilidades. La balanza comercial obluvo un déficil equivalente al 13.2 por ciento dcl PIB, lo cual se explica por la desarticulación productiva de los diferentes sectores económicos y cl luerte flujo de remesas familiares. Sin embargo, a lo largo de esta década se observa una tendencia a la reducción de la vulnerabilidad externa, dado que la relación entre exportaciones e importacioncs aumentó de 47.8 por ciento que tuvo en 1991 a 61.1 por ciento en 1999, lo cual es positivo considerando que este ha sido un año adverso para las exportaciones. Sin embargo, las exportaciones apenas crecieron 2.1 por ciento a lo largo del año, en contraste con las altas tasas de crecimiento que hubo en años anteriores. La caída en las exportaciones se explica por la baja en los precios del café, la pérdida de dinamismo de las exportaciones de las exportaciones no tradicionales al resto de Centroamérica, las cuáles crecieron a 2.2 por ciento en 1999, y de las exportaciones de maquila, que también crecieron menos que el año anterior.
En cuanto al déficit en cuenta corriente, éste llegó a 1.6 por ciento del PIB al mes de septiembre, el cuál es bastante bajo en comparación con el déficit en la balanza comercial. Esto se logra por el enorme flujo de remesas familiares, las cuales representaron aproximadamente el 11.2 por ciento del PIB en 1999. Por su parte, la cuenta de capital experimentó un saldo positivo -de 0.7 por ciento del PIB al mes de septiembre-, el cual es mucho menor que los saldos positivos obtenidos en años anteriores.

Finalmente, la deuda externa pública llegó al 23.1 por ciento del PIB, manteniéndose a niveles similares a años anteriores. Mientras que la relación entre los servicios de la deuda y las exportaciones de bienes alcanzó el 21.8 por ciento.

En las secciones siguientes se abordan estos resultados con mayor detalle. En la sección 2 se expone la evolución de la producción y el empleo; en la 3, la evolución de los macro precios, la inflar ción, las tasas de interés real, los salarios reales y el tipo de cambio real; en la sección 4 se aborda la situación del sector financiero, específicamente la evolución del seclor bancario, los agregados monetarios y los fondos de pensiones; en la sección 5 se analiza la evolución de las finanzas públicas; en la 6, la evolución del sector externo; y en la sección 7 se presentan las reflexiones finales.

\section{Evolución de la producción y el empleo}

En esta sección se realiza un breve análisis sobre la evolución del producto por habitante y sobre el país en general. Asimismo se tratan de identificar cuáles fueron los sectores que más contribuyeron a este crecimiento a través de un breve análisis sectorial del producto.

\subsection{Evolución del producto}

De acuerdo con los datos publicados por el Banco Central de Reserva, el producto interno bruto (PIB) creció alrededor de 2.2 por ciento. Por otro lado, el crecimiento de la población se estima en aproximadamente 2.1 por ciento anual; por tanto, el crecimiento del producto per cápita del año pasado se estima en 0.1 por ciento (Gráfica 1). Al contar con un avance prácticamente nulo del producto por habitante, el país en su conjunto no ha mejorado en términos de nivel de vida de la población. En El Salvador, durante los últimos cuatro 
años, lejos de ayudar a disminuir las condiciones de pobreza del país, a través de un crecimiento robusto y sostenido del producto per cápita, la tendencia ha sido hacia la disminución de la tasa de crecimiento, llegando a ser prácticamente nula en 1999, y negativa en 1996. Revertir esta tendencia es imperativo si se desea mejorar el nivel de vida de la población.

\section{Gráfica 1}

PIB/hab. y tasa de variación (precios constantes 1990=100)

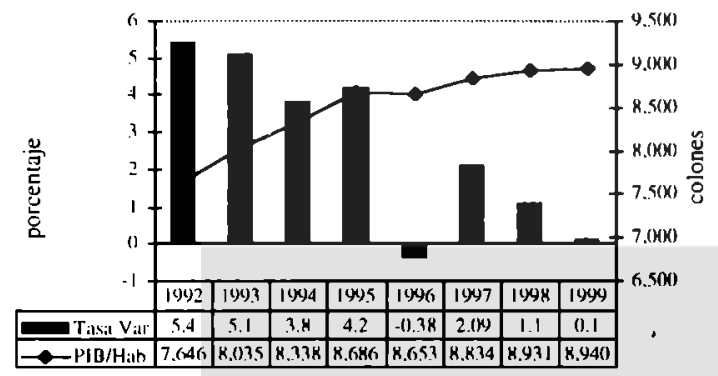

Fuente: Banco Central de Reserva y cálculos propios.

El promedio de crecimiento del producto interno bruto por habitante de los últimos 4 años es de 0.7 por ciento. Si ésta fuera la tasa de crecimiento promedio de la economía a largo plazo, duplicar el PIB por habitante, en términos reales, tomaría aproximadamente 98 años $^{2}$. En 1999, el producto interno bruto per cápita a precios constantes de 1990 se ubicó en $\notin 8,939.6$ por año, que - aun siendo mayor que el nivel alcanzado a principios de la década de 1990 - todavía se encontró por debajo del PIB per cápita más alto que se ha registrado en el país (en 1978), el cual equivalía a $\not 9,305.9$. Es decir, todo el crecimiento de la década de los noventa no ha bastado para colocar al país en su posición previa al conflicto armado. Para poder llegar a este nivel, todavía nos va tomar varios años.

\section{Gráfica 2 \\ Tasa de crecimiento del PIB \\ (En porcentajes)}

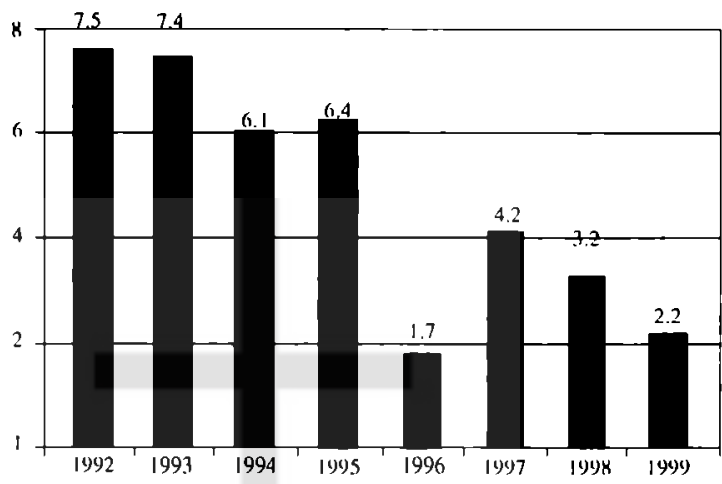

Fuente: Banco Central de Reserva y cálculos propios

Comparando la tasa de crecimiento con el resto de países centroamericanos, El Salvador obtuvo el penúltimo lugar en cuanto a tasas de crecimiento, sólo arriba de Honduras, país que todavía se encuentra sufriendo las devastadoras consecuencias del paso del huracán Mitch. De acuerdo con datos publicados de manera preliminar por la CEPAL, Honduras creció en -2 por ciento, Guatemala 3.5 por ciento, Nicaragua 6 por ciento y Costa Rica 7.5 por ciento ${ }^{3}$. Aún con nuestra tan destacada estabilidad macroeconómica y con el enorme flujo de divisas que provienen de las remesas de los inmigrantes salvadoreños, no fuimos capaces de crecer a tasas que contribuyeran a reducir la situación de pobreza del país. En 1999, por cuarto año consecutivo no se alcanzó la ya baja mela de crecimiento propuesta por el programa monetario del Banco Central de Reserva - luego de la revisión realizada en julio, el BCR estableció para el año pasado una meta de crecimiento de entre 2.5 y 3.5 por ciento, respectivamente-. Esta es una señal que no debería pasar desapercibida por las autoridades monetarias; pese a eso, no se ven signos de cambio en el gobierno al analizar las nuevas metas del programa monetario para el presente año. Todo

2. Álvaro Trigueros Argüello, "El crecimiento económico en El Salvador de 1950 a 1996", Realidad Económica y Social, 61, 1998.

3. CEPAL, "Balance preliminar de las economías de América Latina y El Caribe", 1999. 
parece indicar que nuevamente la estabilidad se convierte en un fín en sí mismo, aún y cuando se tienen señales claras de los costos en producción y bienestar que esto implica para la población.

Adicionalmente, vale la pena señalar que el indicador del crecimiento, tal como se ha presentado hasta el momento, está muy lejos de reflejar la evolución del bienestar social, dado que no toma en cuenta ciertos factores para poder reflejarlo mejor. Entre estos factores, en El Salvador destacan el deterioro ambiental, los gastos derivados de la situación de violencia, el alto subempleo y la desigualdad en la distribución del ingreso y la riqueza.

Si bien, es necesario que exista un entorno macroeconómico estable como condición para lograr un desarrollo económico en el país, se necesitan tasas de crecimiento mayores si es que se quiere avanzar en la solución del problema de la pobreza, pero también se requieren medidas especiales para reducir la exclusión y la desigualdad. Aquí se encuentra uno de los principales retos de la polílica económica.

\subsection{Crecimiento por sectores}

Luego de presentar en forma global el desempeño de la economía, en esta sección se abordan los sectores más relevantes dentro de aquella, ya sea por la importancia que tienen individualmente dentro de la economía o por efectuarse algún cambio importante dentro de su evolución normal ${ }^{4}$.

Entre los sectores que más contribuyeron al crecimiento del año pasado se encuentran (en orden descendente): la industria, la agricultura y electricidad, el gas y el agua, con tasas de crecimiento superiores al logrado por la economía en su conjunto.

\subsubsection{La industria}

Por su parte, la reducción en el crecimiento de la industria se puede explicar por la reducción en la tasa de crecimiento de las exportaciones de maquila en los años 1998-1999, y también por la difícil situación del sector frente a la competencia de productos importados, resultado de la desgravación arancelaria. Adicionalmente, la Inversión Intcrna Bruta Pública decreció en 3.6 por ciento y la privada creció tan sólo 2.8 por ciento, contra crecimientos de 1.3 y 6.8 por ciento en 1998, respectivamente, lo cual pudo haber afectado la evolución del sector industria, así como la de otros sectores.

\section{Cuadro 1}

Tasas de crecimiento de algunos sectores en 1999(1)

Sector Tasa de crecimiento

$\begin{array}{ll}\text { Industria manufacturera } & 4.0 \\ \text { Agricultura } & 3.7 \\ \text { Electricidad, gas y agua } & 3.5 \\ \text { Construcción } & 2.2 \\ \text { Comercio } & 1.7\end{array}$

Fuente: CEPAL. (1): Cifras preliminares.

Para realizar el análisis del sector industrial se utilizará el Índice de Volumen de la Producción Industrial (IVOPI), indicador construido por el Banco Central de Reserva (BCR). De acuerdo coñ la evolución de la tasa de variación (promedio móvil 12 meses), durante 1999 se evidencia una franca desaceleración de la actividad industrial, llegando a una tasa de variación de 5.04 por ciento, en noviembre, contra 8.89 por ciento en 1998. Lo anterior es coherente con la información presentada por FUSADES durante su informe de coyuntura del IV trimestre $1999^{\varsigma}$, en el cual el indicador de producción del sector industria fue sensiblemente menor al de 1998 en todos los trimestres.

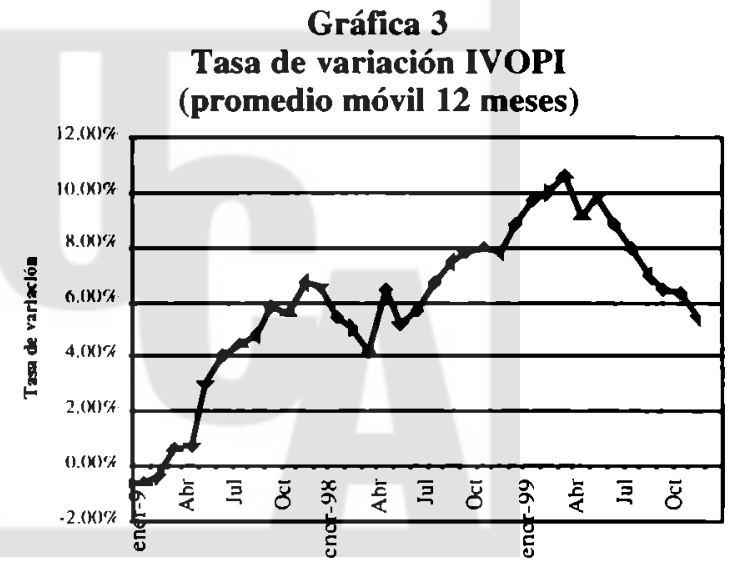

Fuente: Banco Central de Reserva.

4. Esta sección también estuvo condicionada a la disponibilidad de información con que se contaba hasta el momento.

5. FUSADES. "Informe de Coyuntura IV trimestre 1999", San Salvador, 2000. 
Durante 1999 y a diferencia del año anterior, hubo una disminución de la actividad económica en el sector industrial, lo cual es preocupante si al mismo tiempo se constituyó en el principal sector que impulsó el crecimiento de PIB. Tal como se mencionó en el informe de coyuntura anterior, "se observa que existe una tendencia al debilitamiento de la actividad en el sector" ${ }^{\prime \prime}$ y hasta el momento dicha tendencia continúa.

\subsubsection{Construcción}

\section{Cuadro 2 \\ IVAE: Sector construcción variación anual de la media móvil 12 meses (En porcentajes)}

\begin{tabular}{ccccccccccccc}
\hline & Ene. & Feb. & Mar. & Abr. & May. & Jun. & Jul. & Ago. & Sep. & Oct. & Nov. & Dic. \\
\hline 1998 & 4.81 & 4.89 & 6.10 & 3.30 & 3.11 & 3.63 & 3.89 & 3.47 & 4.19 & 4.05 & 4.48 & 5.61 \\
1999 & 5.52 & 6.28 & 6.00 & 7.35 & 6.45 & 6.11 & 6.00 & 6.25 & 4.21 & 3.49 & 3.02 & \\
\hline
\end{tabular}

Fuente: Banco Central de Reserva

El sector construcción ha venido experimentando una crisis desde hace varios meses atrás; sin embargo, a partir de septiembre de 1998 la tasa de crecimiento del promedio móvil de 12 meses del IVAE inició una recuperación hasta septiembre del año pasado, mes en que nuevamente las tasas de crecimiento se redujeron y son menores a las que se obtuvieron durante los mismos meses del año de 1998 (Cuadro 2 y Gráfica 4).

\section{Gráfica 4}

IVAE: Sector construcción variación anual (media móvil 12 meses)

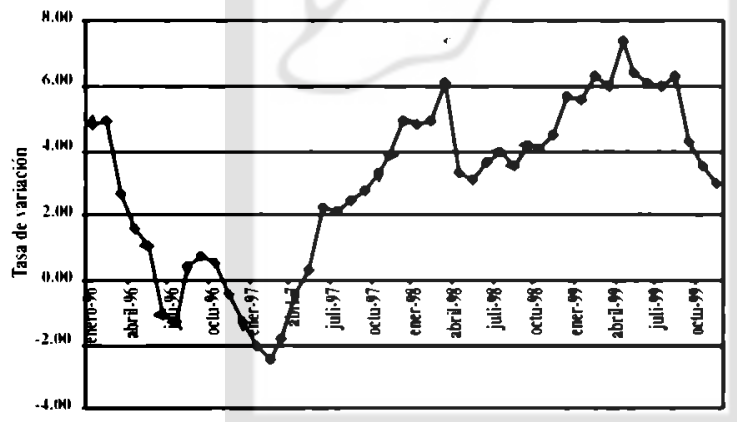

Fuente: Banco Central de Reserva.
El poco dinamismo del sector construcción responde al atraso en la ejecución de la inversión pública; no obstante, en los últimos meses del año se finalizaron obras de infraestructura vial, sobre todo en el área metropolitana de San Salvador. Hasta septiembre del año pasado, la inversión pública era de 2,268 millones de colones, 123 millones inferior a la meta programada. Por otro lado, el sector construcción se vio afectado por la reducción experimentada en la demanda de viviendas y las altas tasas de interés para el financiamiento de éstas, que mantienen deprimida la demanda.

\subsubsection{Electricidad, gas y agua}

En cuanto al sector de Electricidad, gas y agua, cabe mencionar la privatización de las plantas de generación de energía geotérmica, y la inversión directa de 250 millones de dólares que se ha realizado en el sector.

¿Qué se puede esperar para el próximo año? La meta de crecimiento propuesta por el Banco Central es de 3.5 por ciento para este año. Al respecto existen algunos factores favorables para lograrlo. Entre los externos se pueden mencionar los precios internacionales del café (aunque en la actualidad ya no se encuentran tan altos, muchos de los contratos ce-

6. Departamento de Economía de la UCA, "Análisis de coyuntura económica, primer semestre de 1999", ECA, 611. 1999. 
rrados a fin de año fueron a futuro, es decir, se liquidan en el presente año y fueron contratados a precios altos). Las expectativas de que se mejoren las condiciones de la Iniciativa de la Cuenta del Caribe (ICC) son favorables; de ser así, se daría impulso a un sector que ha venido empujando el crecimiento de las exportaciones, el sector de maquila básicamente textil, adicionalmente este sector podría verse beneficiado si es que finalmente se firma el Tratado de Libre Comercio (TLC) con México.

Entre los aspectos que pueden influir negativamente continua el shock de los precios del petróleo, una variable conflictiva de manejo por parte del gobierno. México no ha prorrogado el Acuerdo de Alcance Parcial (AAP) que mantenía con el país - por medio del cual se otorgaban beneficios arancelarios a una parte importante de productos nacionales- y tampoco se ha logrado firmar el TLC. En este escenario no se obtienen los beneficios del TLC y se perdieron los que existían con el AAP. El azúcar, uno de los principales productos de exportación tradicionales, sufrió un revés debido a la decisión de Estados Unidos de América de disminuir al mínimo la cuota de exportación asignada a El Salvador. Por tal motivo, los productores se encuentran a la búsqueda de nuevos mercados europeos para compensar la baja en el volumen de exportación. Adicionalmente, el sector cañero-azucarero está pasando por una crisis interna que no ayuda a mejorar sus perspectivas. Los desequilibrios fiscales presionan, por lo que se proyecta una inversión pública baja.

Es difícil predecir qué factores pesan más en el crecimiento que pueda experimentar el país; no obstante, desde nuestro punto de vista será difícil alcanzar la meta de crecimiento proyectada por el Banco Central. Sin embargo, es necesario decir que, aun si se alcanza la tasa de crecimiento planteada, ésta es insuficiente para incidir de manera real en el proceso de desarrollo y combate contra la pobreza del país, que es necesario replantear las metas en función de lograr un objetivo de crecimiento mayor y con más equidad.

\subsection{Evolución del empleo}

La tasa de desempleo total de los últimos cinco meses de 1999, son menores que las existentes durante los mismos meses en 1998; sin embargo, la tendencia durante los últimos meses del año pasado fue creciente, ésta ha venido aumentando desde 5.1 por ciento de la PEA (la menor tasa registrada) hasta 6.5 por ciento para noviembre de 1999 , contra 7.7 por ciento para noviembre de 1998. En términos generales se puede decir que el indicador de desempleo ha mejorado con respecto al año pasado, aunque se debe mencionar que los datos existentes aún no cubren un período suficientemente largo, dado que dicho indicador se ha empezado a entregar cada mes a partir de agosto de 1998.

Sin embargo, respecto al indicador de subempleo, éste ha empeorado con respecto a 1998, 10dos los valores comprendidos entre agosto y noviembre de 1999 son superiores a los presentados durante 1998; asimismo, al obtener el promedio de subempleo existente por año, existe un aumento de un punto porcentual en la tasa comprendida entre 1998 y 1999.

\section{Gráfica 5}

Tasa de desempleo y subempleo total promedio móvil 3 meses (porcentajes)

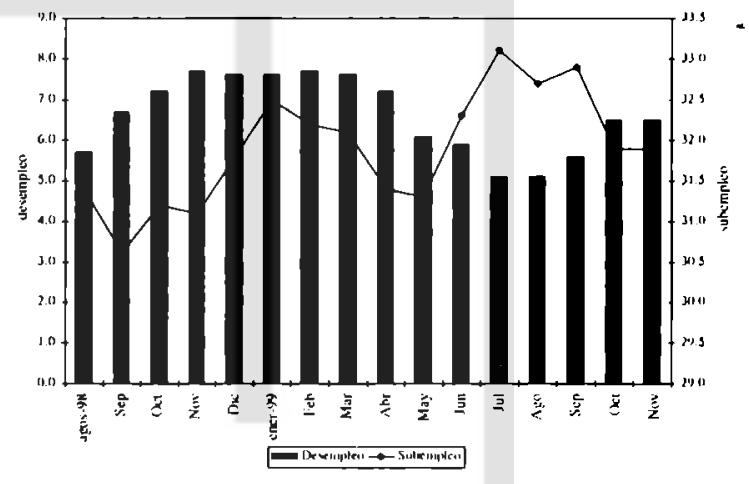

Fuente: DIGESTYC.

Cuadro 3

Tasa promedio anual de desempleo y subempleo

\begin{tabular}{lrr}
\hline & 1998 & 1999 \\
\hline Desempleo promedio & 7.0 & 6.4 \\
Subempleo promedio & 31.2 & 32.2 \\
\hline
\end{tabular}

Fuente: Elaboración propia sobre la base de datos de DIGESTYC.

La contraparte del análisis del subempleo y el empleo se basa en la evolución de empleo, para lo cual se ha utilizado el total de cotizantes efectivos al Sistema de Ahorro para Pensiones (SAP), es decir el total de afiliados al SAP que han recibido un ingreso con base al cual han declarado y pagado su cotiza- 
ción previsional. Se trata, entonces, de un indicador del empleo existente en el sector formal de la economía - principalmente urbano-; también se ha incluido la tasa de variación mensual.

De acuerdo con los datos, durante el primer semestre del año el total de cotizantes activos venían creciendo a una tasa promedio mensual del 2 por ciento, mientras que en el segundo semestre la tendencia se reviritió y pasó a una lasa negativa de 0.2 por ciento, hasta el mes de noviembre; sin embargo, no se cuenta con cl dato de diciembre para poder comparar el semestre completo.

Con base en estas cifras destaca el hecho, a partir de las cifras de desempleo y empleo, de que aproximadamente dos terceras partes de la población tienen algún lipo de empleo, mientras que el tercio restante se encuentra desempleada o subempleada. Si a esto añadimos que quienes poseen algún tipo de empleo en su mayoría son empleos poco remunerados y de baja calidad, nos encontramos que, a pesar del crecimiento obtenido a lo largo de la década de los noventa, este crecimiento no ha sido capaz de llegar a un gran porcentaje de la población.

\section{Gráfica 6}

Cotizantes activos al SAP y tasa de crecimiento

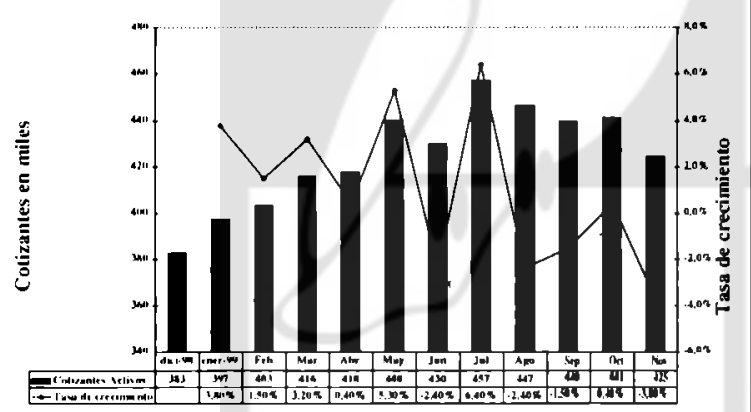

Fuente: Superintendencia de pensiones.

\section{Evolución de los precios}

En esta parte se analiza la evolución que han mostrado los principales macro precios de la economía nacional. Estos son: la inflación o creci- miento del nivel general de precios, los salarios reales, las tasas de interés nominales y reales, y el tipo de cambio real.

En cuanto al nivel de precios, si bien la inflación - medida a través de la evolución del IPC - informa un decrecimiento general de los precios del 1 por ciento, esto se debe principalmente a shocks externos y a la aplicación de una política monetaria restrictiva por parte del Banco Central de Reserva'. Lo anterior se apoya al analizar la evolución de la inflación permanente o núcleo inflacionario, un indicador más preciso que minimiza la influencia de factores externos y aleatorios; de acuerdo con este indicador, la inflación permanente punto a punto a noviembre fue de 0.8 por ciento. Finalmente, al observar la evolución hacia el alza del IPRI durante el último semestre de 1999, se espera que el comportamiento del IPC lienda también hacia el alza en los primeros meses del presente año, ya que existe evidencia empírica en otros países de que el IPRI anticipa, en cierta medida, el comportamiento del IPC. Adicionalmente sigue existiendo presión hacia el alza de los precios al menos por dos razones: por el continuo aumento en los precios internacionales del petróleo, por el incremento esperado de la demanda agregada al contar con un presupuesto aprobado por la Asamblea Legislativa, desde el año pasado, y por la entrada de divisas por la venta de café a precios internacionales favorables.

\subsection{Nivel general de precios}

Al comparar la inflación -medida a través del Índice de Precios al Consumidor (IPC) - de El Salvador con la de otros países de Latinoamérica, la de El Salvador se encuentra entre las más bajas del continente; en este aspecto se informa un decrecimiento de precios del 1 por ciento entre diciembre de 1998 y diciembre de 1999. Lo anterior puede destacarse en términos de que el Banco Central de Reserva de El Salvador (BCR) ha cumplido con la parte de su misión relativa a "consolidar y mantener la estabilidad monetaria" ; sin embargo, existen algunas consideraciones que pueden comentarse respecto al logro obtenido. Si bien la inflación general presentó una deflación del uno por ciento en mil novecientos noventa y nueve, el

7. La política monetaria se analiza en la sección 4.1.

8. El otro compromiso establecido en la misión de dicho instituto tiene que ver con "Propiciar la estabilidad y competitividad del sistema financiero", el cual no forma parte del análisis que se desarrolla en este acápite. 
grupo de misceláneos presentó un crecimiento de precios de 3.6 por ciento. Dentro de este grupo se encuentran los gastos en salud, educación, transporte público y privado, y comunicaciones entre los principales subgrupos que lo componen; la mayoría de ellos corresponden con aquellos rubros o sectores de los cuales se escuchan quejas por parte de la población.

\section{Cuadro 4}

Precios internacionales del petróleo año 1999

(En dólares/barril)

\begin{tabular}{ccccccccccc}
\hline Mar. & Abr. & May. & Jun. & Jul. & Ago. & Sep. & Ocl. & Nov. & Dic. \\
\hline 11.22 & 10.83 & 14.56 & 15.3 & 17.06 & 17.53 & 19.93 & 21.68 & 24.81 & 23.89 \\
\hline
\end{tabular}

Fuente: Banco Central de Reserva.

El impacto del incremento en los precios del petróleo" (Cuadro 4) se refleja en los subgrupos de transporte privado y público, pero debido a su pequeña ponderación ( 7.68 y 2.53 por ciento, respectivamente) no afecta mayormente el índice general. Sin embargo, considerando que el petróleo es uno de los sectores claves de la economía, en el scntido de que es un abastecedor de energía, no es de extrañar que estos incrementos en el precio del petróleo se filtren, poco a poco, al resto de sectores económicos, tal y como sucedió con las crisis del petróleo en 1974 y 1979. Por su parte, el grupo de vivienda, el cual también muestra un incremento de precios del 1.7 por ciento, incluye entre sus subgrupos a Electricidad y Combustible (con una ponderación del 3.8 por ciento dentro del índice general), nuevamente es recogido el impacto de la subida en los precios del petróleo.

Por otro lado, el aumento de las colegiaturas, que constituye una inversión en capital humano que realizan las familias en sus hijos, el cual sí incide de manera significativa en el potencial de desarrollo que como país podemos alcanzar, tampoco afecta demasiado en el índice general al contar con una ponderación de 3.59 por ciento.

En cuanto a la baja de precios, los alimentos constituyen el grupo que mayor decremento presenta - con un 5.2 por ciento-; esto podría explicarse, en parte, por la mayor competitividad de Guatemala frente a nosotros debido a las devaluaciones que ha experimentado el quetzal (mientras nosotros continuamos con un tipo de cambio prácticamente fijo); es decir, después de la devaluación, los productos que importamos de Guatemala son más baratos y gran parte de las frutas, verduras y legumbres que consumimos provienen de ese país. Finalmente, el grupo vestuario, tal como se apuntó en el análisis de coyuntura del primer semestre del año pasado" por la apertura de nuestra economía hacia la importación de este tipo de productos, y la evolución de los precios del vestuario y el calzado en los mercados internacionales".

9. Este incremento es la respuesta del mercado internacional a la disminución en la producción del crudo que los países productores del mismo, agrupados en la OPEP, han acordado junto con México y Noruega, quienes planean seguir aplicando dicha política al menos hasta mediados de año 2000 . Adicionalmente, el riguroso invierno que ha sufrido el hemisferio norte ha causado que las reservas se agoten más rápidamente de lo normal, debido al gasto en calefacción que ha significado los rigores del invierno. El Wall Street Journal del 14 de febrero de 2000 , menciona que el precio del crudo se mantuvo en $\$ 29.43$ en el New York Mercantile Exchange, y que un analista de Merril Lynch "indicó que los precios pueden llegar a los 45 dólares el barril, si la OPEP no pone más petróleo en el mercado".

10. Departamento de Economía de la UCA, “Análisis de coyuntura económica: Primer semestre de 1999", ECA, $611,1999$. 


\section{Cuadro 5 \\ Índice de Precios al Consumidor \\ Variación porcentual anual (punto a punto) por grupos base: diciembre $1992=100$}

\begin{tabular}{|c|c|c|c|c|c|c|c|c|c|c|}
\hline \multirow[b]{2}{*}{ Mes } & \multicolumn{2}{|c|}{ General } & \multicolumn{2}{|c|}{ Alimentos } & \multicolumn{2}{|c|}{ Vivienda } & \multicolumn{2}{|c|}{ Vestuario } & \multicolumn{2}{|c|}{ Misceláneos } \\
\hline & 1998 & 1999 & 1998 & 1999 & 1998 & 1999 & 1998 & 1999 & 1998 & 1999 \\
\hline Enero & 1.5 & 3.1 & -0.7 & 5.4 & 5.9 & 2.7 & 0.3 & -1.2 & 1.5 & 0.8 \\
\hline Febrero & 1.3 & 2.6 & -1.1 & 4.2 & 6.1 & 2.3 & -0.1 & -0.9 & 1.1 & 1.2 \\
\hline Marzo & 1.5 & 2.0 & -0.3 & 2.4 & 5.7 & 2.5 & -0.5 & -0.6 & 1.1 & 1.3 \\
\hline Abril & 2.7 & 0.1 & 2.0 & -1.3 & 6.2 & 1.6 & -0.7 & -0.8 & 1.3 & 1.4 \\
\hline Mayo & 3.5 & -1.0 & 3.7 & -4.0 & 6.5 & 1.4 & -0.9 & -0.8 & 1.4 & 1.6 \\
\hline Junio & 3.2 & -1.2 & 3.1 & -4.3 & 6.5 & 1.2 & -0.7 & -0.9 & 1.1 & 1.6 \\
\hline Julio & 2.8 & -1.1 & 1.7 & -3.9 & 6.7 & 1.3 & -0.9 & -1.0 & 2.0 & 1.3 \\
\hline Agosto & 2.2 & 0.1 & 0.7 & -1.5 & 6.3 & 1.6 & -0.9 & -0.8 & 1.8 & 1.5 \\
\hline Septicmbre & 1.5 & 1.5 & -0.2 & 0.9 & 5.3 & 1.8 & -0.9 & -0.8 & 1.3 & 2.5 \\
\hline Oclubre & 1.9 & 2.0 & 0.7 & 1.9 & 5.5 & 1.8 & -0.9 & -1.0 & 1.2 & 2.9 \\
\hline Novicmbre & 4.3 & -0.7 & 7.1 & -4.2 & 4.4 & 1.8 & -0.8 & -1.3 & 1.0 & 2.9 \\
\hline Diciembre & 4.2 & -1.0 & 6.9 & -5.2 & 4.6 & 1.7 & -0.8 & -1.5 & 0.7 & 3.6 \\
\hline
\end{tabular}

Fuente: Dirección General de Estadística y Censos.

Como se ha señalado anteriormente, las bajas lasas de inllación encuentran su explicación en una política monetaria restrictiva y en una demanda agregada débil. Respecto a la demanda agregada débil, viendo cada uno de sus componentes ayuda a conlirmar el argumento, hay una caída del ritmo de inversión tanto pública como privada, la lasa de crecimiento de las exportaciones ha disminuido considerablemente, y aunque no hay datos de consumo para linales de año, pero como se observa más abajo, la evolución de los salarios reales no indicaría aumentos por el lado del consumo. Vale la pena señalar el peligro que envuelve una demanda agregada deprimida que genere capacidad ociosa, acumulación de inventarios o ambas cosas en las empresas, que acompañada de dellaciones $o$ inllaciones bajas y tasas de interés altas que presionan a las empresas con altos costos linancicros e ingresos deprimidos. En este contexto es previsible el aumento de la cartera morosa de los bancos de 4.8 por ciento, en septiembre de 1998, a 7.3 por ciento el mismo mes del año pasado"l y el aumento de los bienes recibidos en calidad de pago por las instituciones bancarias de 693.2 millones de colones a 1,168.7 millones de colones en el mismo período de referencia.

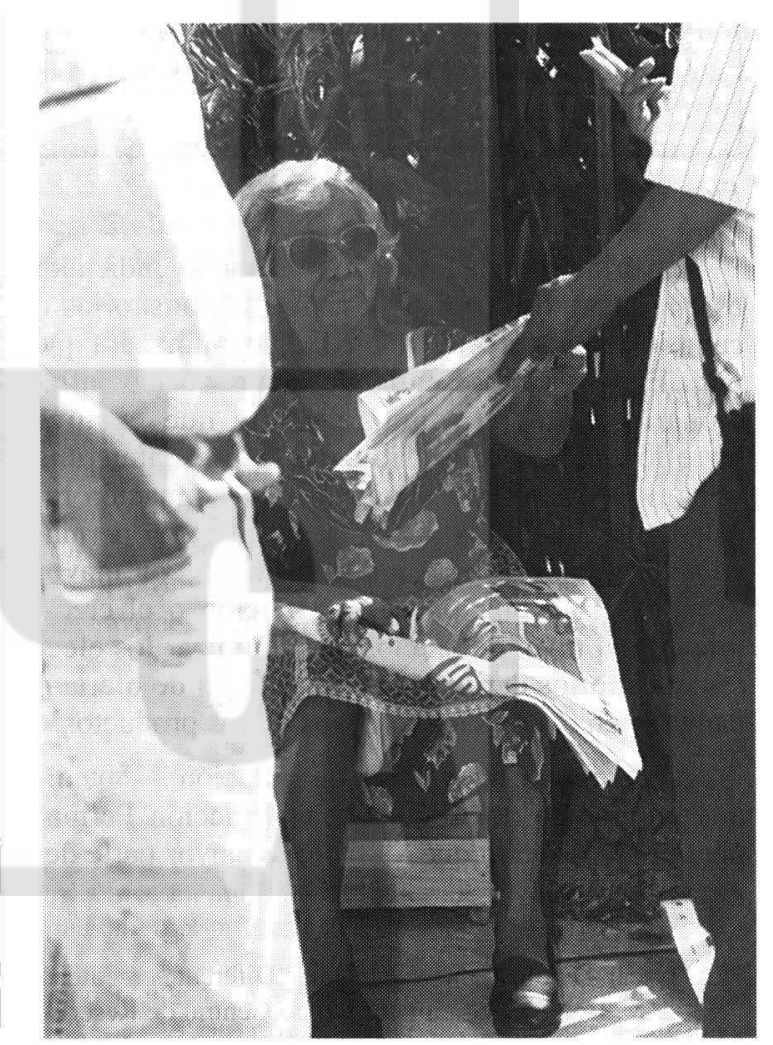

11. Ver sección 4.2 más abajo. 


\subsection{Otras medidas de inflación o crecimiento del nivel de precios}

A pesar de que la inflación, medida a través del IPC, se considera como una medida estándar a nivel mundial para conocer cómo evolucionan los precios, existen otros indicadores que cuentan con ciertas características que no posee el IPC y, por tanto, sirven de información complementaria. En la actualidad, el Banco Central de Reserva genera un indicador al que denominan inflación permanente o núcleo inflacionario, la cual se justifica "en el hecho que la política monetaria debe disponer de medidas de inflación libres de efectos transitorios"'?

\section{Gráfica 7}

Inflación normal y permanente (variación anual punto a punto)

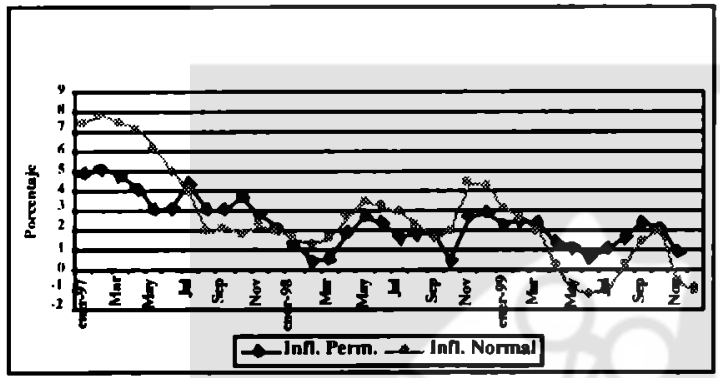

Fuente: Banco Central de Reserva.

La principal característica de dicho indicador es que pretende eliminar los efectos transitorios o cambios en los precios relativos, de tal manera que para El Salvador se entiende como núcleo inflacionario a "la inflación relevante que excluye aquellos bienes y servicios que presentan una volatilidad manifiesta. Por tanto, la estimación resultante es una señal fiable de la inflación permanente"". Es decir, este indicador mide con mayor exactitud la evolución de la inflación o el crecimiento del nivel de precios, al minimizar los efectos transitorios derivados de los shocks de oferta o cambios en los precios relativos de los productos.

Al comparar los valores de inflación -obtenidos por medio del IPC y de la Inflación Permanente- se observa que, durante la mayor parte del año anterior, esta última se encuentra por encima de la inflación normal, lo cual es más concordante con la apreciación de la población sobre el nivel de precios (Gráfica 7). Por otra parte, la inflación permanente es una medida más correcta para evaluar el logro o no de la meta inflacionaria propuesta por el BCR. Desde esta perspectiva, la inflación permanente informa un crecimiento anual, en noviembre, de 0.8 por ciento versus una deflación cercana al 1 por ciento que indica el IPC, más de un punto y medio por arriba. Es válido preguntarse por qué el valor reportado a través del indicador de la inflación permanente es mayor que el medido a través de la inflación normal. Como se mencionó anteriormente, la inflación permanente busca eliminar los efectos de los shocks externos, por ejemplo el ocasionado por el huracán Mitch. Así, 1998 cerró con una inflación de 4.2 por ciento debido, entre otros aspectos, a los efectos de este huracán, dentro del IPC se reflejó en el aumento de precios que registró el grupo de alimentos (6.9 por ciento), debido a que dicho fenómeno natural arrasó con gran parte de las cosechas creando escasez; sin este shock externo posiblemente la inflación de 1998 hubiese sido más baja. De haber sido así, la diferencia en el nivel de precios entre diciembre de 1998 y diciembre de 1999 hubiera sido menor, tal como lo indica la inflación permanente, apoyando la tesis de que la medida de inflación permanente o núcleo inflacionario es una mejor medida, en términos de evaluar el desempeño de la política monetaria aplicada por el Banco Central de Reserva, en función del objetivo de estabilidad de precios.

La formación de precios en la economía pasa por varios procesos desde que el producto es vendido por primera vez por el productor, hasta que llega a manos del consumidor final. El IPC es un indicador de cómo evolucionan los precios finales de los productos, es decir, el que perciben los consumidores finales, o sea, el comercio al por menor o minorista. Existen otros indicadores como el Índice de Precios al por Mayor (IPM) y el Índice de Precios Industriales (IPRI). El primero recoge la evolución de los precios en el primer canal de comercialización, es decir, tal como su nombre lo

12. Oscar Ovidio Cabrera Melgar, "Diferentes medidas de inflación relevante para la política monetaria de El Salvador", Boletín Económico, Banco Central de Reserva, 124, 1998.

13. Ibid. Los subgrupos que se excluyeron de la estimación son cereales y derivados, pescados y mariscos, huevos, frutas frescas y envasadas, vegetales y legumbres y electricidad y combustible. 
indica, en la comercialización al por mayor; y el segundo, los precios de venta a la salida fábrica obtenidos por los establecimientos industriales en las transacciones que estos efectúan, excluyendo los gastos de Iransporte y el Impuesto al Valor Agregado (IVA) facturado ${ }^{14}$.

Desde encro de 1998, el Banco Central de Reserva está calculando el IPRI; el hecho de que se trate de un indicador de reciente elaboración presenta algunas ventajas sobre el IPM ${ }^{15}$. Debido a que capla los precios en la primera transacción, de alguna manera se comporta como un indicador que permite conocer con anterioridad el comportamiento del IPC; en ese sentido, se esperaría que los aumentos o las disminuciones en el IPRI se reflejen posteriormente en incrementos o decrementos en el IPRI (aunque para el país aún no cxiste evidencia empírica suficiente como para alirmar tal causalidad). Por otro lado, también puede conocer con menor retraso los cambios en los precios internacionales de los bienes, que son insumos para la producción de productos industriales. El Cuadro 6 muestra la evolución de dicho indicador durante el año recién pasado. Durante el segundo semestre de 1999, todas las variaciones mensuales fueron positivas, a excepción de octubre (que fue de -0.28 por ciento), la variación anual punto a punto para noviembre de 1999 fue de 8.48. Este hecho podría indicarnos que durante los primeros meses de este año podría revertirse la tendencia deflacionaria, que indica la evolución del IPC, lo cual también se apoya por el incremento de los precios internacionales del petróleo $y$, por ende, de sus derivados, y por un aumento de la demanda agregada, producto del incremento de los precios del calé durante los męses recién pasados. El ingreso de estos recursos al país se retrasa en el tiempo, con lo cual su efecto es posterior a la fechas en que se dan las variaciones en el mercado mundial.

\author{
Cuadro 6 \\ Índice de Precios Industriales \\ Variación porcentual mensual y anual año 1999 \\ base: enero $1998=100$
}

\begin{tabular}{lccc}
\hline Mes & Índice & $\begin{array}{c}\text { Variación } \\
\text { mensual }\end{array}$ & $\begin{array}{c}\text { Variación } \\
\text { anual }\end{array}$ \\
\hline Enero & 100.37 & 5.06 & 0.37 \\
Febrero & 100.63 & 0.26 & 0.65 \\
Marzo & 100.33 & -0.3 & 0.76 \\
Abril & 101.48 & 1.15 & 2.13 \\
Mayo & 101.25 & -0.23 & 2.49 \\
Junio & 102.01 & 0.75 & 3.48 \\
Julio & 103.85 & 1.8 & 5.74 \\
Agosto & 104.49 & 0.62 & 7.8 \\
Septiembre & 105.04 & 0.52 & 8.16 \\
Octubre & 104.74 & -0.28 & 7.34 \\
Noviembre & 105.03 & 0.27 & 8.48 \\
\hline
\end{tabular}

Fuente: Banco Central de Reserva de El Salvador.

\subsection{Salarios reales}

Para analizar la evolución del salario real en el país, se han utilizado dos indicadores elaborados a partir del salario mínimo vigente y del salario o ingreso promedio de cotización informado por el ISSS, y luego por la Superintendencia de Pensiones. Se han obtenido los salarios en colones constantes de 1990 y, con base en ellos, se obtiene un índice de salario real, cuya evolución se recoge en la Gráfica 8.

A pesar de que el salario mínimo no fue objeto de ningún incremento estipulado por la Comisión Nacional del Salario Mínimo, su valor adquisitivo no se vio deteriorado durante 1999, y se cerró el año con un salario mínimo real casi un 4 por ciento mayor al promedio de 1998. Lo anterior se explica por dos razones: en primer lugar, por un efecto precio,

14. Banco Central de Reserva, Departamento de Cuentas Macroeconómicas, "El Índice de Precios Industriales, IPRI, alternativa para medir el comportamiento de la inflación en el primer canal de comercialización", Boletín Económico, 128, 1999.

15. Para una mayor información sobre el tema, ver Banco Central de Reserva, Departamento de Cuentas Macroeconómicas, "El Índice de Precios Industriales, IPRI, alternativa para medir el comportamiento de la inflación en el primer canal de comercialización", Boletín Económico, 128, mayo-junio, 1999. 
pues al existir una deflación de I por ciento para 1999, el salario mínimo se incrementa en igual proporción si el valor nominal de salario se mantiene constante; en segundo lugar, por un incremento del salario nominal promedio del año 1999 con respecto al de 1998, ya que a partir de abril de 1998 se incrementó de $₫ 38.50 /$ día a $\not 42.00 /$ día, de lo que resulta que el salario nominal promedio para 1998 fue de $\$ 40.83 /$ dia, mientras que para 1999 fue de 42 colones por día. Sin embargo, aún se mantiene la brecha en salario real con respecto a la década pasada, encontrándose un 20 por ciento por debajo del salario mínimo real de 1988.

\section{Gráfica 8}

Índice de salarios reales $(1990=100)$

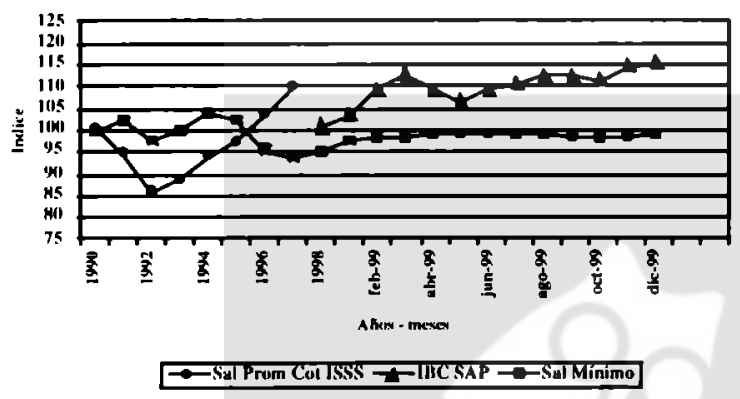

Fuente: Elaboración propia con base en el salario mínimo, los salarios medios cotizables reportados por el ISSS hasta 1998, y el Ingreso Base de Cotización (IBC) reportado por la Superintendencia de Pensiones.

El índice de salario real, medido por medio del salario medio cotizable, muestra una tendencia al alza a lo largo de la década y aumentó 14 por ciento respecto a 1990 , debido al fenómeno deflacionario -que ya se mencionó antes- y al incremento nominal del ingreso base de cotización, el cual presenta un promedio de $1,816.65^{16}$. Sin embargo, en 1999, el salario medio cotizable real creció apenas 0.7 por ciento.

El análisis de la evolución de los salarios reales permite hacer dos conclusiones. Primero, que los salarios mínimos reales han mostrado un estan- camiento a lo largo de la década y que su poder de compra se encuentra muy por debajo del nivel de 1988. En segundo lugar, dado que en 1999, así como en años anteriores, el salario promedio real ha crecido, y que la gran mayoría de asalariados considerados en el cálculo del salario promedio reciben el salario mínimo, se puede concluir que hay un deterioro en la distribución del ingreso laboral en El Salvador en los últimos años. Sin embargo, esto no permite concluir que existe un deterioro en la distribución del ingreso nacional, debido a que no está tomando en cuenta el ingreso no laboral, pero no apunta a una mejora del mismo. Con base en los datos de la Encuesta de Hogares y Propósitos Múltiples (EHPM), la distribución del ingreso ha variado poco a lo largo de la década y sigue siendo una de las más concentradas en América Latina. Según la EHPM de 1998, el 20 por ciento más pobre de la población recibía 5.7 por ciento del ingreso, y el 20 por ciento más rico de la población recibía 48 por ciento del ingreso ${ }^{17}$.

\subsection{Tasas de interés}

La tasa de interés continúa siendo elevada, como resultado de la combinación de la política monetaria y un sistema de tipo de cambio fijo, del elevado déficit fiscal y de la falta de competencia en el sistema bancario.

\section{Gráfica 9}

Tasa de interés básica pasiva, activa y encaje mínimo legal

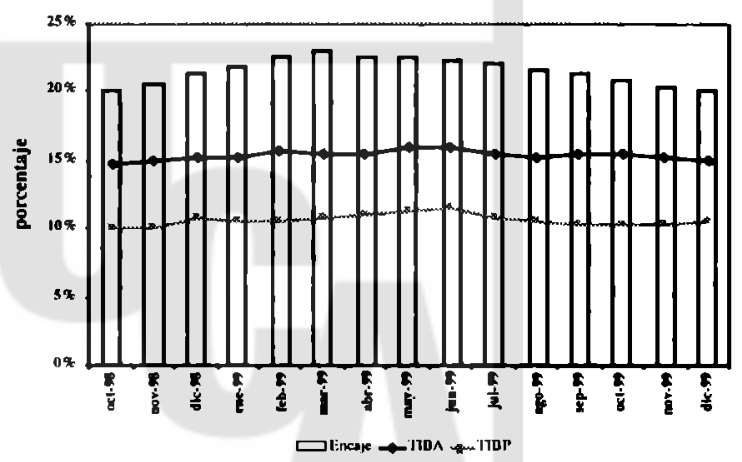

Fuente: Banco Central de Reserva de El Salvador y ABANSA.

16. Calculado como el promedio simple de los Ingresos Base de Cotización promedio mensuales, reportado por la Superintendencia de Pensiones para el Sistema de Ahorro para Pensiones.

17. Cfr. Abby Córdova y Zéphyr Dominique, "Crecimiento, pobreza y distribución del ingreso en El Salvador durante la década de los noventa", documento no publicado, 2000. 
A lo largo de 1999, las tasas de interés altas también fueron reforzadas por la política del Banco Central de Reserva, ya que incrementó el encaje mínimo legal desde noviembre de 1998, llegando a un máximo del 23 por ciento en abril de 1999; a partir de allí comenzó a disminuir lentamente hasta alcanzar 20 por ciento el 24 de noviembre (Gráfica 9). Aquí es importante destacar que no es totalmente válido afirmar que la política de encaje del BCR se ha relajado, es más apropiado decir que dicha política ha retornado a los niveles anteriores, y si se toma el conjunto de medidas adoptadas por el Banco CenIral (como se detalla en la sección 4), se puede afirmar que la política monetaria sigue siendo restrictiva.

La Tasa de Interés Básica Activa (TIBA) alcanzó su máximo en mayo de 1999, tanto en tér- minos nominales como reales ${ }^{14}$; es decir, presenta un retraso de 2 meses con respecto al encaje. La Tasa de Interés Básica Pasiva (TIBP), por su parte, muestra su máximo en junio en términos nominales; sin embargo, tomando en cuenta la inflación (deflación), alcanzó su máximo en mayo. Lo que es importante destacar son las elevadas tasas de interés reales que enfrentan lo agentes económicos -empresas e individuos-, es decir, lo que les significa el costo real del dinero que piden en préstamo, por ejemplo, para que a un empresario le sea factible realizar un préstamo con fines de mejorar su negocio, debe al menos alcanzar un rendimiento real de 15 por ciento (promedio de la TIBA para 1999) sólo para poder cancelar el préstamo, si no alcanza esa rentabilidad se verá en problemas para poder cancelar el préstamo y posiblemente caerá en mora.

\begin{tabular}{|c|c|c|c|c|c|}
\hline \multirow[b]{2}{*}{ MES } & \multicolumn{4}{|c|}{$\begin{array}{l}\text { Cuadro } 7 \\
\text { Tasas de interés nominales y reales }\end{array}$} & \multirow[b]{2}{*}{$\begin{array}{c}\text { TIBA } \\
\text { real }\end{array}$} \\
\hline & TIBP & TIBA & Inflación & $\begin{array}{l}\text { TIBP } \\
\text { real }\end{array}$ & \\
\hline Dic-91 & $13.42 \%$ & $18.17 \%$ & $9.83 \%$ & $3.27 \%$ & $7.60 \%$ \\
\hline Dic-92 & $14.10 \%$ & $18.21 \%$ & $19.93 \%$ & $-4.86 \%$ & $-1.44 \%$ \\
\hline Dic-93 & $14.00 \%$ & $18.79 \%$ & $12.09 \%$ & $1.70 \%$ & $5.98 \%$ \\
\hline Dic-94 & $13.15 \%$ & $19.32 \%$ & $8.89 \%$ & $3.91 \%$ & $9.57 \%$ \\
\hline Dic-95 & $16.04 \%$ & $19.99 \%$ & $11.37 \%$ & $4.19 \%$ & $7.74 \%$ \\
\hline Dic-96 & $11.97 \%$ & $16.68 \%$ & $7.36 \%$ & $4.29 \%$ & $8.68 \%$ \\
\hline Dic-97 & $12.73 \%$ & $15.68 \%$ & $1.93 \%$ & $10.60 \%$ & $13.49 \%$ \\
\hline Dic-98 & $10.74 \%$ & $15.12 \%$ & $4.21 \%$ & $6.26 \%$ & $10.46 \%$ \\
\hline Enc-99 & $10.47 \%$ & $15.17 \%$ & $3.13 \%$ & $7.12 \%$ & $11.68 \%$ \\
\hline Feb-99 & $10.56 \%$ & $15.66 \%$ & $2.62 \%$ & $7.74 \%$ & $12.71 \%$ \\
\hline Mar-99 & $10.93 \%$ & $15.41 \%$ & $1.95 \%$ & $8.81 \%$ & $13.20 \%$ \\
\hline Abr-99 & $11.06 \%$ & $15.58 \%$ & $0.15 \%$ & $10.89 \%$ & $15.41 \%$ \\
\hline May-99 & $11.20 \%$ & $15.93 \%$ & $-1.03 \%$ & $12.36 \%$ & $17.14 \%$ \\
\hline Jun-99 & $11.59 \%$ & $15.87 \%$ & $-1.20 \%$ & $12.94 \%$ & $17.27 \%$ \\
\hline Jul-99 & $10.89 \%$ & $15.44 \%$ & $-1.07 \%$ & $12.09 \%$ & $16.69 \%$ \\
\hline Ago-99 & $10.54 \%$ & $15.25 \%$ & $0.13 \%$ & $10.40 \%$ & $15.10 \%$ \\
\hline Sep-99 & $10.38 \%$ & $15.46 \%$ & $1.45 \%$ & $8.80 \%$ & $13.81 \%$ \\
\hline Oct-99 & $10.40 \%$ & $15.42 \%$ & $1.96 \%$ & $8.28 \%$ & $13.20 \%$ \\
\hline Nov-99 & $10.27 \%$ & $15.29 \%$ & $-0.70 \%$ & $11.04 \%$ & $16.10 \%$ \\
\hline Dic-99 & $10.65 \%$ & $15.09 \%$ & $-1.02 \%$ & $11.79 \%$ & $16.28 \%$ \\
\hline
\end{tabular}

Los datos muestran que, a lo largo de la década de los noventa, las tasas de interés nominales han ido disminuyendo a medida que la inflación se ha reducido; sin embargo, en términos de tasa de

18. La lórmula utilizada para el cálculo de la tasa de interés real es: $r=1-[(1+i) /(1+p)]$, donde $r$ es la tasa de interés real. $i$ la tasa de interés nominal, y $p$ la tasa de inflación. 
interés real, ésta ha venido aumentando (Cuadro 7). A lo largo de 1999, las tasas de interés real han continuado en aumento, mientras que las tasas de interés nominal no han seguido disminuyendo conforme con la reducción en la inflación. Dados los niveles de inflación y crecimiento que exhibe la economía, es plausible pensar que la política monetaria que está llevando a cabo el Banco Central de Reserva es demasiado restrictiva, y causa que la represión en la demanda agregada tenga costos en crecimiento. Adicionalmente, hay que tomar en cuenta que existen otros factores que presionan al alza en las tasas de interés, como la política cambiaria en combinación con la política monetaria, la política fiscal y la falta de competencia en el sistema bancario.

\subsection{Tipo de cambio efectivo real}

El índice de lipo de cambio efectivo real (ITCER), a diferencia del tipo de cambio nominal, toma en cuenta los cambios en los niveles de precio entre nuestro país y los principales socios comerciales. Adicionalmente, toma en cuenta las variaciones en el tipo de cambio de nuestros socios comerciales con respecto al dólar. En tal sentido, csta variable nos viene a indicar la evolución de la competitividad de nuestras exportaciones con respecto a nuestros principales socios comerciales. Una reducción del ITCER indica una depreciación de nuestra moneda, o un aumento de la competitividad precio de nuestras exportaciones; un aumento del ITCER indica lo contrario. La Gráfica lo mucstra la evolución del tipo de cambio electivo real y se observa que, a lo largo de la década de los noventa, ha existido una fuerte apreciación del colón $y$, por tanto, un fuerte deterioro en la competitividad precio de nuestras exportaciones.

Los lactores que explican este fenómeno son varios, de acuerdo con las variables involucradas en el cálculo del ITCER. Uno de los factores que explican esta apreciación es el flujo de divisas de los salvadoreños que viven en el extranjero, en el sentido de que crean un exceso de oferta de divisas. Si bien el Banco Central de Rescrva mantiene un sistema de tipo de cambio fijo de facto, la moneda se aprecia porque los precios relativos de los biencs no transables entre los transables aumentan, lo que aumenta los costos de operación en el país y genera cl fenómeno de la enfermedad holandesa. Otro factor es que mientras el país mantiene un sistema de tipo de cambio fijo, nuestros vecinos centroamericanos han devaluado sus monedas con respecto al dólar y, por tanto, con respecto al colón salvadoreño. Además, en el transcurso de muchos años, nuestra inflación ha sido mayor que la inflación de algunos de nuestros principales socios, como Estados Unidos, Alemania y Japón; no obstante, este fenómeno no se ha dado en el último año, debido a nuestra baja inflación. En todo caso, a lo largo de la década éste es uno de los factores que se han convertido en obstáculo para el desarrollo de nuestras exportaciones. En la medida que se logren mantener tasas de inflación bajas y se decida continuar con un sistema de tipo de cambio fijo, el país podrá aumentar su competitividad en la medida que logre aumentos continuos en la productividad real de las empresas exportadoras.

Gráfica 10

Índice de tipo de cambio efectivo real (índice: 1990=100)

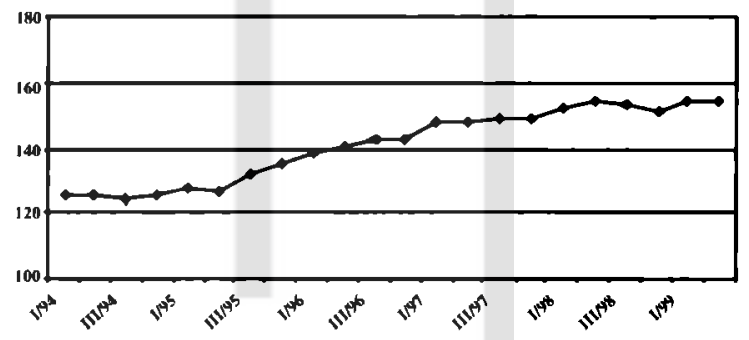

Fuente: Fondo Monetario Internacional. IMF Information Notice System.

\section{Sector Financiero}

En esta sección se evalúa la evolución de la política monetaria y el estado actual del sector financiero. Entre los hechos más relevantes que afectan al sector, tenemos el aumento del encaje hasta marzo de 1999, luego comienza a bajar hasta retornar, en forma gradual, a su nivel inicial en el segundo semestre; la disminución terminó el 24 de noviembre. Asimismo continúa en aumento la mora de los bancos y se ven ciertas señales de concentración en la industria; se aprobó la nueva Ley de Bancos, que viene a sustituir la Ley de Bancos y Financieras; y, finalmente, el incremento en los fondos de pensiones está saturando el mercado de capitales en el país. 


\subsection{Agregados monetarios}

En la década de los noventa, El Salvador ha experimentado un proceso fuerte de profundización financiera, el cual se ve en la evolución de los principales agregados monetarios. Con respec10 a la oferta monetaria, M1, que corresponde al medio circulante, es decir numerario y depósitos a la vista, el crecimiento promedio anual a lo largo de la década ha sido de 12.5 por ciento, y como porcentaje del producto interno bruto, $\mathrm{Ml}$ se ha mantenido alrededor de un promedio de 9.4 por ciento. Respecto a M2, que corresponde a una definición más amplia de oferta monetaria, incluyendo además de $\mathrm{M} 1$, los depósitos de ahorro y a plazo. Así, a lo largo de toda la década la oferta monetaria M2 ha crecido en todos los años, pasando de 28.4 por ciento del PIB, en 1989, a 44.1 por cicnto en 1999. En cuanto al crecimiento anual entre 1990 y 1994, las tasas de crecimiento de M2 se mantuvieron por encima del 20 por ciento, pero a partir de 1995 —aunque siguieron siendo positivas- éstas comenzaron a disminuir cada año, hasta llegar a una tasa de crecimiento anual de 6.4 por ciento, en 1999. Esta última es la tasa de cre cimiento más baja de la oferta monetaria M2 en toda la década. Un comportamiento similar tiene la definición de oferta monetaria, M3, que además de incluir todo lo que contiene $M 2$, incluye otros instrumentos monetarios, como depósitos en moneda extranjera, títulos valores, cédulas hipotecarias y otros (Cuadro 8). La evolución de M2 y M3, en los últimos 5 años, es el resultado de una política monetaria restrictiva, que se reflejó con mayor fuerza en 1999. Como ya se señaló en la sección anterior, esto se ha manifestado en la reducción de la inflación, que alcanzó cifras negativas a finales de 1999. Según un informe de ABANSA, El Salvador está entre los cuatro sistemas bancarios más profundos de América Latina'19.

\section{Cuadro 8}

Agregados monetarios

(millones de colones al 31 de diciembre de cada año)

\begin{tabular}{rrrrrrrrrrr}
\hline & \multicolumn{1}{c}{ M1 } & \multicolumn{1}{c}{ M1/PIB } & Crec. & \multicolumn{1}{c}{ M2 } & M2/PIB & Crec. & M3 & M3/PIB & Crec. \\
\hline 1989 & $3,150.90$ & $9.8 \%$ & & $9,141.90$ & $28.4 \%$ & & $9,789.04$ & $30.4 \%$ & \\
1990 & $3,846.20$ & $10.5 \%$ & $22.1 \%$ & $11,647.40$ & $31.9 \%$ & $27.4 \%$ & $12,635.02$ & $34.6 \%$ & $29.1 \%$ \\
1991 & $4,079.60$ & $9.6 \%$ & $6.1 \%$ & $14,250.20$ & $33.5 \%$ & $22.3 \%$ & $14,915.08$ & $35.0 \%$ & $18.0 \%$ \\
1992 & $5,375.40$ & $10.8 \%$ & $31.8 \%$ & $18,255.20$ & $36.6 \%$ & $28.1 \%$ & $19,254.37$ & $38.6 \%$ & $29.1 \%$ \\
1993 & $6,042.60$ & $10.0 \%$ & $12.4 \%$ & $23,235.70$ & $38.5 \%$ & $27.3 \%$ & $24,243.33$ & $40.2 \%$ & $25.9 \%$ \\
1994 & $6,661.90$ & $9.4 \%$ & $10.2 \%$ & $28,680.00$ & $40.5 \%$ & $23.4 \%$ & $30,169.20$ & $42.6 \%$ & $24.4 \%$ \\
1995 & $6,955.30$ & $8.4 \%$ & $4.4 \%$ & $31,824.10$ & $38.3 \%$ & $11.0 \%$ & $34,015.40$ & $40.9 \%$ & $12.7 \%$ \\
1996 & $8,173.20$ & $9.1 \%$ & $17.5 \%$ & $36,402.00$ & $40.3 \%$ & $14.4 \%$ & $39,874.60$ & $44.2 \%$ & $17.2 \%$ \\
1997 & $8,014.80$ & $8.2 \%$ & $-1.9 \%$ & $39,834.60$ & $40.6 \%$ & $9.4 \%$ & $44,773.50$ & $45.6 \%$ & $12.3 \%$ \\
1998 & $8,708.00$ & $8.4 \%$ & $8.6 \%$ & $43,601.30$ & $42.0 \%$ & $9.5 \%$ & $49,046.50$ & $47.2 \%$ & $9.5 \%$ \\
1999 & $9,880.00$ & $9.4 \%$ & $13.5 \%$ & $46,376.00$ & $44.1 \%$ & $6.4 \%$ & $52,640.00$ & $50.1 \%$ & $7.3 \%$ \\
\hline
\end{tabular}

Fuente: Banco Cental de Reserva y elaboración propia.

Adicionalmente, se puede ver la evolución del los depósitos y los créditos de los bancos. Las tasas de crecimiento de ambos agregados han venido disminuyendo desde 1997, llegando a valores cercanos al cinco por ciento para los últimos meses del año. Este fenómeno, además de estar in- fluido por una política monetaria restrictiva, especialmente el último año, en que el aumento del encaje legal afectó el crecimiento de los créditos y los depósitos, también es reflejo de una reducción en el crecimiento económico.

19. INFORMABANSA, Año $2, \mathrm{~N}^{\circ} 11$, enero, 2000. 
Gráfica 11

Crecimiento de los depósitos y del crédito

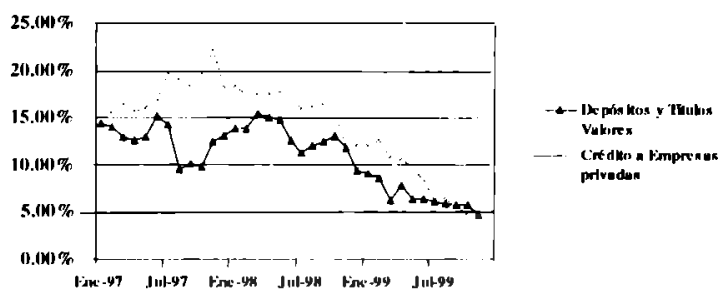

Fuente: Banco Central de Reserva, Revista trimestral y boletín estadístico mensual.

En este contexto, es notable señalar que la composición de los activos de la base monetaria ha sufrido cambios importantes en los últimos años, entre los que destacan el papel cada vez más importante de los activos externos netos y la emisión de títulos valores emitidos por el Banco Central de Reserva. En primer lugar, al mes de noviembre de 1999, los activos externos netos representaban 100 por ciento de la base monetaria, comparado con 64.3 por ciento que representaban en 1996. Esto está relacionado con el flujo de remesas familiares a la economía, por lo cual el Banco Central de Reserva se ha convertido en un comprador neto de divisas para mantener fijo el tipo de cambio (ver también la sección 6.3). En segundo lugar, para lograr sus objetivos de inflación, el BCR ha tratado de esterilizar el aumento en la base, que resulta de la compra de dólares, mediante la emisión de títulos valores; así tenemos que los tílulos comprados por el sistema han subido de 2,890 millones de colones en 1996, a 6,340.8 millones de colones en noviembre de 1999. En tercer lugar, destaca que entre los principales compradores de títulos valores, los bancos han ido perdiendo participación, pero la bolsa de valores ha incrementado su papel de intermediador de dichos títulos, las Asociaciones de Fondos para Pensiones comenzaron a aparecer como compradores importantes en 1998, y las instituciones ftnancieras no monetarias han incrementado su parlicipación considerablemente (Cuadro 9).

A manera de reflexión, resulta interesante que gran parte de los fondos de las Asociaciones de

\section{Cuadro 9}

Base monetaria

(Saldos en millones de colones)

\begin{tabular}{lrrrr}
\hline Fuentes & 1996 & 1997 & 1998 & \multicolumn{1}{c}{ Nov/1999 } \\
\hline I. Activos cxtcrnos & $7,692.1$ & $10,678.9$ & $13,962.7$ & \multicolumn{1}{c}{$14,150.5$} \\
1. Activos externos brutos & $9,620.8$ & $12,793.1$ & $15,445.9$ & $16,783.3$ \\
2. Préstamos ext. de med. y largo plazo & $-1,928.7$ & $-2,114.2$ & $-1,483.2$ & $-1,433.6$ \\
\hline I1. Activos internos .etos & $4,262.3$ & $2,348.0$ & 356.8 & $-1,202.2$ \\
I. Crédito al sector financiero & $3,513.4$ & $3,686.7$ & $4,167.7$ & $4,469.2$ \\
2. Crédito al sector públ. no financiero & $3,871.0$ & $4,039.5$ & 629.1 & 322.4 \\
3. Oblig. con inst. finan. No monetarias & -945.3 & $-1,369.1$ & -739.9 & -433.4 \\
4. Otros activos netos & $1,553.0$ & $1,623.5$ & $1,645.7$ & 2003.1 \\
5. Títulos Valores comprados por & $-2,890.0$ & $-4,493.9$ & $-4,104.4$ & $-6,340.8$ \\
a. Bancos comerciales y financieras & -855.8 & $-1,114.3$ & -513.6 & -353.6 \\
b. Inst. financ. No monetarias & -493.1 & -529.1 & -1.168 .6 & $-1,554.2$ \\
c. AFP's & $n . a$. & $n .9$. & -168.3 & -495.9 \\
d. Bolsa de Valores & $-1,541.1$ & $-2,850.6$ & $-2,253.9$ & -3.937 .1 \\
6. Encaje en moneda extranjera & -839.8 & $-1,138.7$ & $-1,241.4$ & $-1,222.7$ \\
III. Base monetaria & $11,954.4$ & $13,026.8$ & $14,319.5$ & $14,150.4$ \\
\hline
\end{tabular}

Fuente: Banco Central de Reserva, Revista Trimestral y Boletín Estadístico Mensual. 
Fondos para Pensiones, los bancos comerciales y la bolsa de valores, que supuestamente deberían estar destinados al financiamiento de actividades productivas, están siendo utilizados para invertir en títulos de estabilización monetaria, de allí que, en cierta forma, la política de tipo de cambio fijo, aunado a la política monetaria, están compitiendo por los fondos prestables con la inversión privada; lo que también se refleja en la tasa de interés real, como se observó antes. También hay que agregar que el cambio drástico en la composición de la base monetaria, hace pensar que existe un acto deliberado por parte de las autoridades monetarias del país para encaminar la economía hacia un proceso de dolarización, o a lo mejor hacia un sistema de caja de convertibilidad, después del fallido intento en 1996, sólo que de una forma menos evidente. Lejos de ser esto una sospecha infundada, en parte viene a ser corroborado por una afirmación del Fondo Monetario Internacional ante una consulta realizada en el país: "Los Directores notaron que las autoridades estaban considerando moverse eventualmente a un régimen de caja de convertibilidad. Ellos observaron que antes de dar tal movimiento, debería darse un fortalecimiento sustancial en la posición fiscal y la del sistema financiero, junto con un incremento adicional en las reservas internacionales" ${ }^{20}$.

\subsection{La situación de los bancos}

En esta sección se estudia la evolución de la competencia en la industria bancaria y el estado actual de los indicadores financieros de los bancos; en este sentido, se observa un incremento en la concentración en la industria bancaria y el continuo aumento de la mora bancaria.

El Departamento de Economía de la UCA analizó la concentración en la industria bancaria, para el primer semestre de 1998, y se encontraron algunas señales de mayor competencia en la industria, con la conversión de algunas financieras a bancos y la introducción de nuevos bancos al sistema. A continuación se describe la evolución de la concentración y en la industria bancaria, a partir de lo cual resalta el hecho de que la tendencia encontrada anteriormente se ha revertido, lo cual muestra un mayor grado de concentración en la industria ${ }^{21}$. Utilizando el índice de Herfindahl-Hirschman (IHH) para observar la evolución de la concentración en la industria bancaria, nos encontramos que éste ha aumentado de 1,274.54 -en marzo de 1997- a 1353 - en septiembre de 1999 - lo que ubica a la industria en una estructura de mercado con competencia monopolística, según la clasificación del Departamento de Justicia de Estados Unidos. La cifra tuvo un salto importante entre el tercer $y$ cuarto trimestre de 1998, cuando se realizó la fusión entre Bancorp y el Banco Promérica, y cuando se distribuyó la cartera de Credisa entre algunos de los bancos más grandes. También hubo otro salto más alto al fusionarse el Banco Atlacatl con el Banco de Comercio, en el tercer trimestre de 199922. Así mismo, a finales de 1999 se anunció la fusión entre el Banco Agrícola Comercial y el Banco Desarrollo, porque se pronostica que en el 2000, el índice IHH dará otro salto importante hasta llegar a 1738.2, aproximando la estructura de la industria bancaria a la categoría de oligopolio, de acuerdo con la clasificación del Departamento de Justicia de Estados Unidos ${ }^{23}$. Alternativamente, si se utiliza como índice de concentración la cuota de mercado de los cuatro bancos más grandes (I-4), encontramos que las conclusiones son similares, ya que el índice de concentración pasa de 62.2 por ciento en marzo de 1997, a 66 por ciento en septiembre de 1999, dando un salto importante el segundo trimestre de 1999 con la fusión del Banco Atlacatl con el Banco de Comercio. Asimismo, con el anuncio de la fusión entre el Banco Agricola y el Banco Desarrollo, la participación de los cuatro bancos más grandes sería de 74.3 por ciento, según la estructura actual de los depósitos (Gráfica 12).

20. IMF, "IMF Concludes Article IV Consultation with El Salvador", Public Information Notice, PIN, No. 99/104, 1999, p. 3.

21. Departamento de Economía de la UCA, "Análisis de coyuntura económica: Primer semestre de 1998", ECA, $599,1999$.

22. Si bien las fechas oficiales de fusión se realizaron con anterioridad, es hasta este período en que aparecen consolidadas las cuentas de los bancos en las publicaciones de la Superintendencia del Sistema Financiero.

23. El cálculo del cambio para el año 2000 se hizo bajo el supuesto de que la distribución de los depósitos de los bancos, a septiembre de 1999, no va a cambiar sustancialmente. 
Gráfica 12

Índices de concentración en la industria bancaria

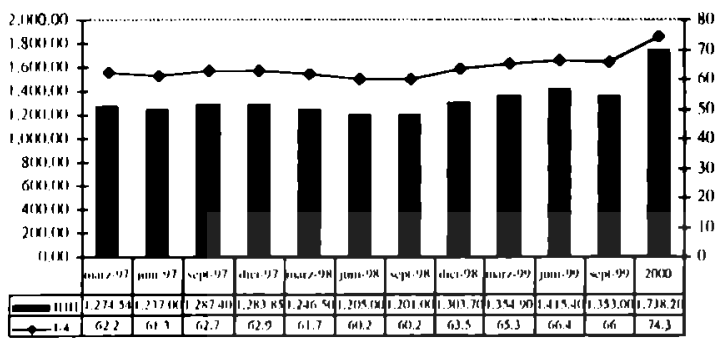

Ficente: Cálculos propios con información de la SSF.

En el Cuadro 12 se muestra la cuota de mercado de los bancos a partir tanto de la captación de depósitos como del patrimonio de los bancos. A partir del patrimonio sc observa un menor grado de concentración; sin embargo, este sigue siendo elevado, y desde el año 2000, con la fusión del Banco Agrícola Comercial -que hasta septiembre de 1999 concentraba el 23.3 por ciento de los depósitos de los bancos- con el Banco Desarrollo -que concentraba 8.3 por ciento-, los indicadores de concentración subirán aún más.

Respecto a la industria bancaria, resulta interesante que en el contex to de la globalización poco a poco hay mayor presencia extranjera en la banca nacional. Así tenemos que, en la actualidad, el 69 por ciento de la propiedad de las acciones de los bancos pertenece a personas (jurídicas o naturales) con nacionalidad salvadoreña; 10.58 por ciento a personas con nacionalidad nicaragüense; 6.2 por ciento a personas o instituciones con nacionalidad en la Bermudas; 7.49 por ciento a personas o instituciones con nacionalidad en Estados Unidos, y

\section{Cuadro 10}

Cuotas de mercado de los bancos en base al total de depósitos y al patrimonio (En porcentajes)

\begin{tabular}{|c|c|c|c|c|c|c|}
\hline \multirow[b]{2}{*}{ Instilución } & \multicolumn{5}{|c|}{ Depósitos } & \multirow{2}{*}{$\begin{array}{c}\text { Patrimonio } \\
\text { Sep-99 }\end{array}$} \\
\hline & Mar-97 & Mar-98 & Mar-99 & Jun-99 & Sep-99 & \\
\hline I Agrícola & 23.2 & 23.4 & 23.4 & 24.0 & 23.3 & 19.2 \\
\hline 2 Cuscallán & 18.9 & 18.0 & 20.1 & 20.5 & 19.3 & 19.6 \\
\hline 3 Salvadoreño & 11.9 & 11.7 & 13.1 & 12.9 & 12.2 & 11.2 \\
\hline 4 Comercio & 8.2 & 8.6 & 8.7 & 8.9 & 11.1 & 11.1 \\
\hline 5 Desarrollo & 6.7 & 7.1 & 8.1 & 8.3 & 8.3 & 7.1 \\
\hline 6 Bancasa & 5.6 & 5.2 & 5.0 & 5.2 & 5.2 & 5.0 \\
\hline 7 Ahorromet & 4.3 & 5.3 & 6.2 & 6.2 & 5.8 & 6.3 \\
\hline 8 Hipotecario & 4.3 & 3.8 & 3.8 & 3.9 & 3.9 & 3.9 \\
\hline $9 \mathrm{BFA}$ & 1.9 & 2.5 & 2.5 & 2.4 & 2.5 & 3.2 \\
\hline 10 Multivalores & 2.2 & 1.5 & 1.6 & 1.7 & 2.0 & 1.5 \\
\hline II Credomatic & & & & 1.9 & 1.9 & 2.6 \\
\hline 12 Promérica & 0.7 & 0.7 & 1.5 & 1.5 & 1.6 & 1.3 \\
\hline I3 Capital & 0.4 & 0.7 & 0.8 & 1.0 & 1.1 & 3.4 \\
\hline 14 Citibank & 0.6 & 0.8 & 0.8 & 0.8 & 0.8 & 2.8 \\
\hline 15 Unibanco & 1.1 & 1.2 & 0.8 & 0.8 & 0.8 & 1.8 \\
\hline 16 Credisa & 6.1 & 5.4 & 0.7 & 0.2 & 0.1 & \\
\hline 17 Atlacatl & 2.8 & 3.0 & 3.1 & 3.0 & & \\
\hline 18 Bancorp & 1.2 & 1.1 & & & & 0.1 \\
\hline Total & 100.0 & 100.0 & 100.0 & 100.0 & 100.0 & 100.0 \\
\hline I-4 & 62.2 & 61.7 & 65.3 & 66.4 & 66.0 & 61.1 \\
\hline IHH & $1,274.5$ & $1,246.5$ & $1,354.9$ & $1,415.4$ & $1,353.0$ & $1,157.2$ \\
\hline
\end{tabular}

Fuente: Elaboración propia con base en los datos del Boletín Estadístico de Bancos y Financieras, de la Superintendencia del Sistema Financiero. Varios números. 
3.33 por ciento a personas o instituciones con nacionalidad canadiense. Entre los bancos cuyas acciones son, en su mayoría, propiedad de extrajeros están: el Banco Capital (en donde el 99.46 por ciento de las acciones están registradas como propiedad de una institución en las Bermudas), el Banco Ahorromet-Scotiabank (en donde el 53.28 por ciento de las acciones son propiedad del banco canadiense Scotiabank), el Banco Unibanco (en donde el 74.75 por ciento de las acciones son propiedad del Hamilton Bank de Estados Unidos), el Banco Multivalores (en donde el 72 por ciento de las acciones son propiedad de nicaragüenses), y el Banco Credonatic (en donde el 88.1 por ciento de las acciones son propiedad de nicaragüenses). Adicionalmente existe una sucursal del Citibank y oficinas de representación de cuatro bancos extranjeros, Dresdner Bank Lateinamerika, BAC Florida Bank, Banco de Santander y Barclays Bank ${ }^{24}$. El Departamento de Economía (1998, ECA 599) mencionó también la posible incorporación del grupo linanciero mexicano Bancrecer, pero hasta el momento dicho grupo no ha iniciado operaciones en el país. Finalmente, se ha anunciado la pronta apertura del First Conmercial Bank de Taiwan, lo que probablemente sucederá en el 2000.

Así sc liene una paradoja, mientras los indicadores de concentración en la industria bancaria y su pronóstico para el año 2000 señalan una tendencia a mayor concentración, por el lado de la penetración de hancos con capital extranjero se podría considerar que a futuro habría mayor competencia en la industria bancaria. Mientras tanto, las elevadas tasas de interés, aunados a los costos de transacción incluidos como comisiones en varios de los servicios que prestan los bancos, mantienen un costo bastante alto para quienes solicitan crédito a los bancos. En tal sentido, los bancos no están ayudando a sacar al país de su lento crecimiento.

En cuanto al coeficiente de liquidez neta de los bancos, en su conjunto, éste se encuentra por encima del mínimo requerido, y se observa un incremento de septiembre de 1999 a noviembre de 1999. Esto se debe, en parte, al incremento en los activos líquidos de los bancos como estrategia para enfrentar posibles dificultades con el problema del año 2000.

Respecto a la solvencia de los bancos, las estipulaciones legales establecen que en 1999 la relación del fondo patrimonial entre los activos ponderados debe ser igual o superior a 9.2 por ciento; además, se establece que el límite legal será 9.6 por ciento en el año 2000 y 10 por ciento en el año $2001^{25}$. En tal sentido, hasta septiembre de 1999 todos los bancos cumplían con el requisito legal. Para noviembre de 1999, el fondo patrimonial sobre activos ponderados totales llegaba a 10.22 por ciento y, por tanto, la mayoría de los bancos están preparados para el incremento que se realizará a partir del año 2000, con la excepción de cuatro bancos, aunque éstos últimos sí están cumpliendo con el requisito de 1999. En tal sentido, es comprensible el aumento con respecto a septiembre de 1999.

Adicionalmente, la solvencia se evalúa a partir del coeficiente del fondo patrimonial entre el total de pasivos más compromisos futuros y contingencias, para el cual se establece un mínimo legal del 5 por ciento, limitando el grado de expansión en deudas y compromisos que puede asumir la institución. Dicho coeficiente alcanzaba el 7.94 por ciento al mes de noviembre de 1999, para el sistema en su conjunto, y ningún banco muestra estar por debajo del mínimo. En tal sentido, la situación de solvencia de los bancos, evaluada a partir de estos parámetros, es favorable.

El indicador de préstamos vencidos al mes de noviembre de 1999 era de 28.3 por ciento para el Banco de Fomento Agropecuario, y de 19 por ciento para el Banco Hipotecario, lo cual revela la existencia de fuertes debilidades institucionales en la gestión de los mismos, ya que ambas se encuentran muy por encima de los demás bancos. Algunos analistas sostienen que la cifra de la mora bancaria que resulta es alta por la presencia de estas dos instituciones; sin embargo, si multiplicamos los valores anteriores por la participación de estos bancos en la industria a partir de su patrimonio, estos bancos, en conjunto, añaden 1.65 por ciento al indicador de la mora bancaria, lo cual no es una

24. Datos provenientes del Boletín estadístico de Bancos y Financieras, Superintendencia del Sistema Financiero, septiembre. 1999.

25. Con la nueva ley de bancos este requerimiento subirá al 12 por ciento, pero aún desconocemos a partir de cual se hará efectivo. 
gran distorsión. Adicionalmente, la tendencia de la mora bancaria, como se ha visto hasta el momento, muy difícilmente puede se alterada por dos instituciones que en conjunto representan 7.1 por ciento de la industria, si se considera el patrimonio como criterio, ó 6.4 por ciento, si se calcula su participación a partir de los depósitos.

Cuadro 11

Indicadores financieros de los bancos (En porcentajes)

\begin{tabular}{|c|c|c|c|c|c|c|c|c|}
\hline & \multirow{3}{*}{$\begin{array}{l}\text { Liquidez } \\
\text { Coeticiente } \\
\text { liquidez neta }\end{array}$} & \multicolumn{2}{|c|}{ Solvencia } & \multicolumn{3}{|c|}{ Calidad de la Cartera } & \multirow{2}{*}{\multicolumn{2}{|c|}{$\begin{array}{c}\text { Crecimientos } \\
\text { Anuales }\end{array}$}} \\
\hline & & & & Morosidad & Riesgo cred & iticio & & \\
\hline & & $\begin{array}{l}\text { Fondo } \\
\text { patrimonial/ } \\
\text { Activos } \\
\text { ponderados }\end{array}$ & $\begin{array}{l}\text { Fondo } \\
\text { patrimonial/ } \\
\text { Pasivos más } \\
\text { contingencias }\end{array}$ & $\begin{array}{l}\text { Préstamos } \\
\text { vencidos/ } \\
\text { Préstamos } \\
\text { brutos }\end{array}$ & $\begin{array}{l}\text { Catera "D" y } \\
\text { "E"/Total de activos } \\
\text { de riesgo brutos }\end{array}$ & $\begin{array}{l}\text { Reservas de } \\
\text { saneamiento/ } \\
\text { Activos de riesgo } \\
\text { brutos. }\end{array}$ & Depósitos & $\begin{array}{l}\text { Activos } \\
\text { totales }\end{array}$ \\
\hline Mar-97 & $25.70 \%$ & $10.50 \%$ & $8.02 \%$ & $4.36 \%$ & $3.32 \%$ & $3.07 \%$ & $11.90 \%$ & $11.81 \%$ \\
\hline Jun-97 & $27.09 \%$ & $10.50 \%$ & $8.13 \%$ & $3.89 \%$ & $3.56 \%$ & $3.26 \%$ & $13.25 \%$ & $11.61 \%$ \\
\hline Scp-97 & $25.81 \%$ & $10.57 \%$ & $8.31 \%$ & $4.13 \%$ & $3.52 \%$ & $3.31 \%$ & $9.28 \%$ & $10.23 \%$ \\
\hline Dic-97 & $26.05 \%$ & $10.16 \%$ & $7.78 \%$ & $3.91 \%$ & $3.33 \%$ & $3.19 \%$ & $13.57 \%$ & $14.68 \%$ \\
\hline Mar-98 & $26.76 \%$ & $10.16 \%$ & $7.79 \%$ & $4.21 \%$ & $3.69 \%$ & $3.65 \%$ & $16.96 \%$ & $16.51 \%$ \\
\hline Jun-98 & $26.85 \%$ & $10.40 \%$ & $8.04 \%$ & $4.46 \%$ & $3.74 \%$ & $3.66 \%$ & $14.12 \%$ & $16.34 \%$ \\
\hline Sep-98 & $24.93 \%$ & $10.17 \%$ & $8.03 \%$ & $4.78 \%$ & $3.66 \%$ & $3.45 \%$ & $14.09 \%$ & $15.59 \%$ \\
\hline Dic-98 & $24.98 \%$ & $9.45 \%$ & $7.30 \%$ & $5.05 \%$ & $4.98 \%$ & $4.27 \%$ & $9.47 \%$ & $9.60 \%$ \\
\hline Mar-99 & $26.45 \%$ & $10.03 \%$ & $7.61 \%$ & $5.86 \%$ & $4.66 \%$ & $4.27 \%$ & $4.57 \%$ & $9.95 \%$ \\
\hline Jun-99 & $26.67 \%$ & $9.77 \%$ & $7.45 \%$ & $6.37 \%$ & $5.96 \%$ & $4.75 \%$ & $3.84 \%$ & $7.67 \%$ \\
\hline Sep-99 & $25.00 \%$ & $9.45 \%$ & $7.16 \%$ & $7.33 \%$ & $6.76 \%$ & $5.66 \%$ & $5.44 \%$ & $5.52 \%$ \\
\hline Nov-99 & $27.91 \%$ & $10.22 \%$ & $7.94 \%$ & & & & & \\
\hline
\end{tabular}

Fuente: Superintendencia del Sistema Financiero.

En referencia a la morosidad de la cartera, como ya se hizo la observación en análisis anteriores (Departamento de Economía, ECA 603 y 611), ésta ha aumentado en los primeros tres trimestres de 1999, y dados los bajos niveles de actividad económica probablemente se haya incrementado en el cuarto trimestre de 1999 (Cuadro 11). Hasta septiembre de 1999, la cartera en mora de los bancos era de 7.3 por ciento, cifra que se encuentra por encima de la de los países como Chile (1.7 por ciento), Brasil (3.2 por ciento) y Venezuela (6.4 por ciento), pero por debajo de la de otros países como Argentina (9.4 por ciento), Paraguay (9.8 por ciento), Perú (10.3 por ciento), México (11.5 por ciento), Colombia (12.3 por ciento) y Ecuador (15.7 por ciento $)^{26}$. De acuerdo con la evolución económica por sectores - presentada en la segunda sección de este informe-, se espera que el de- terioro de la cartera de préstamos de los bancos continúe a lo largo del 2000.

\subsection{La nueva Ley de Bancos}

Los problemas financieros suscitados en años anteriores, como el escándalo de FinseproInsepro, y la quiebra de uno de los bancos más grandes del país, Credisa, dieron paso a reformas a la Ley de Bancos y Financieras aprobada en 1990. El propósito de dichas reformas es fortalecer la estabilidad financiera y la confianza en el sistema. En el segundo semestre de 1999 se aprobó la nueva Ley de Bancos, cuyas modificaciones más importantes son las siguientes: ${ }^{27}$

- Se limita el uso de la palabra "banco" a las instituciones aprobadas por la Superintendencia del Sistema Financiero (SFF), y se pro-

26. INFOABANSA, Año 2, $\mathrm{N}^{\circ} 11$, enero, 2000.

27. W. Argueta Cazares, "Principales reformas al marco regulatorio del sistema bancario", Boletín Económico, Banco Central de Reserva, noviembre, 1999. 
hibe el uso de la palabra "financiera". El propósito de estas reformas es que el público tenga mayor claridad de cuáles instituciones están autorizadas para captar fondos.

- Se crean las acciones de tesorería, las cuales podrá emitir un banco únicamente cuando existan insuficiencias de capital, es decir cuando el banco se encuentre insolvente; dichas acciones se mantendrán en resguardo. Esta medida facilitaría la reestructuración de un banco por parte del Instituto de Garantía de los Depósitos (IGC).

- Se hacen más estrictos los requerimientos para ser accionista de más del 1 por ciento del capital del banco, y se restringe el acceso a aquellos funcionarios cuyas instituciones financieras hayan sido intervenidas, o hayan requerido aportes del Estado o del IGC, a personas relacionadas con el narcotráfico y el lavado de dinero, o si no sc puede comprobar el origen de los fondos. Se vuelve más estricto el control a los "accionistas relevantes", que son aquellos que poseen 10 por ciento o más de las acciones con derecho a voto.

- La ley trata de introducir la práctica de principios de buena gestión al restringir la cntrada de funcionarios que hayan participado en la quiebra de instituciones financieras, $o$ en lavado de dinero, al exigir a los directores de los bancos mayor compromiso en la entrega de información, y exigir que los gerentes y directores de los bancos tengan como mínimo 5 años de experiencia en cargos de administración superior en instituciones bancarias y financieras.

- Se establecen límites más estrictos en la asunción de riesgo de crédito, al limitar la concentración del crédito a una misma persona o a personas relacionadas.

- La nueva ley aumenta los requerimientos de capital de los bancos, subiendo a 12 por ciento el fondo patrimonial entre el total de activos ponderados por el nivel de riesgo.

- El capital social mínimo requerido para formar un banco es de cien millones de colones.

- Se introduce la deuda subordinada, como fuente de financiamiento de largo plazo al que pueden acceder los bancos en caso de problemas de liquidez. La deuda subordinada se ubica en el último renglón del pasivo en caso de disolu- ción y liquidación del banco deudor, antes de los accionistas.

- Se establecen procedimientos claros de los pasos por seguir en caso de que se detectaran insolvencias bancarias.

- Se incorpora en la ley el título de "Supervisión Consolidada de Instituciones Financieras", que trata de regular la actuación conjunta de conglomerados financieros.

- Se crea el Instituto de Garantía de los Depósitos (IGD), cuya función será garantizar hasta por 55000 colones los depósitos de los ahorrantes en los bancos, en caso de disolución o liquidación de un banco. De acuerdo con la nueva Ley de Bancos, el IGD inicia sus operaciones con un aporte inicial del Banco Central de Reserva por 250 millones de colones, y los recursos irán en aumento con los aportes de las primas que los bancos deberán cancelar. Al llegar los fondos a cierto porcentaje de los fondos protegidos, el IGD deberá pagar al Banco Central de Reserva el aporte inicial.

Por tanto, todas las reformas tienden a hacer más estricto el control del sistema financiero, para darle mayor estabilidad al mismo, lo cual es muy positivo. Sin embargo, al leer la Constitución u otras leyes, vemos que las disposiciones son muy buenas y dan lugar a la creación de una sociedad muy equilibrada, pero la realidad nos muestra algo muy diferente. No es el marco legal lo que va hacer el sistema financiero estable y seguro, aunque es un paso inicial importante, sino más bien las instituciones que harán efectivo el mismo marco legal. Pero las instituciones no se crean de un día para otro $\mathrm{y}$, por tanto, el país todavía tiene que recorrer un largo camino para que nos acerquemos al ideal de un sistema financiero sólido y fuerte.

\subsection{La evolución de los fondos de pensiones}

En esta sección se presentan los datos sobre el valor de los fondos de pensiones y cómo se distribuye la cartera de inversión de dichos fondos. Se observa que existe una creciente oferta de fondos prestables que, a la vez, han creado una demanda por mayores opciones de inversión; sin embargo, la cartera actual de inversiones de las Asociaciones de Fondos para Pensiones, refleja que el mercado está saturado y que no hay suficientes opciones de inversión. Se espera que ésta sea uno de los principales beneficios de la reforma previsional, 
en el sentido que ejerce presión para el desarrollo de los mercados de capitales en el país.

En el Cuadro 12 observamos el número de afiliados al sistema de pensiones, que llegó a 751105 en el mes de noviembre de 1999 -aunque no todo los afiliados cotizan cada mes-. Asimismo se observa un crecimiento sostenido en el fondo de pensiones que, en julio de 1998, comenzó con 60 millones de colones, y en diciembre de 1999 alcanzó la cifra de 1835 millones de colones, lo que representa aproximadamente 1.75 por ciento del producto interno bruto. Lo interesante de esta evolución es cómo se van invirtiendo los fondos de pensiones. Al mes de octubre de 1999, y tomando en cuenta que la composición no tiene una varianza elevada hasta el momento, encontramos que el 97.8 por ciento de los fondos de pensiones estaban invertidos en instrumentos de renta fija, de los cuales el 66.3 por ciento correspondían a instrumentos públicos; 31.5 por ciento correspondían a instrumentos emitidos por bancos y financieras; y apenas el 2.2 por ciento estaba invertido en instrumentos de renta variable, de los cuales casi en su totalidad correspondían a la empresa Telefónica de El Salvador. A menos de dos años de haber iniciado la reforma de pensiones, el sistema ya encuentra un obstáculo en su desarrollo, el cual consiste en la falta de opciones para invertir, lo que viene a representar un reto para el desarrollo de mercado de capitales en el país. En esta línea se tiene que en el tercer trimestre de 1999, las Asociaciones de Fondos para Pensiones participaron con un 48.39 por ciento del monto negociado en el mercado secundario de la Bolsa de Valores de El Salvador ${ }^{2 k}$, y conforme vaya creciendo el fondo de pensiones se espera que esta participación aumente. Lo crítico es que mientras que para la bolsa las Asociaciones de Fondos para Pensiones representan un alto porcentaje de participación en el mercado, para las Asociaciones de Fondos para Pensiones las opciones de inversión productiva en la bolsa representan un porcentaje mínimo.
Cuadro 12

Sistema de Ahorro para Pensiones

(personas y millones de colones)

\begin{tabular}{lllr}
\hline \multicolumn{1}{c}{ Mes } & Afiliados & & $\begin{array}{c}\text { Cartera } \\
\text { nominal }\end{array}$ \\
\hline Jul-98 & 375,999 & C & 60 \\
Ago-98 & 423,774 & C & 127 \\
Sep-98 & 471,067 & C & 202 \\
Oct-98 & 521,683 & C & 260 \\
Nov-98 & 547,758 & C & 339 \\
Dic-98 & 569,972 & C & 419 \\
Ene-99 & 588,388 & C & 505 \\
Feb-99 & 607,549 & C & 604 \\
Mar-99 & 622,374 & C & 724 \\
Abr-99 & 633,045 & C & 842 \\
May-99 & 655,605 & C & 944 \\
Jun-99 & 671,555 & C & 1,031 \\
Jul-99 & 691,813 & C & 1,171 \\
Ago-99 & 705,316 & C & 1,268 \\
Sep-99 & 718,720 & C & 1,360 \\
Oct-99 & 731,940 & C & 1,539 \\
Nov-99 & 751,105 & C & 1,665 \\
Dic-99 & & C & 1,835 \\
\hline
\end{tabular}

Fuente: Superintendencia de Pensiones.

Por otra parte, es necesario reconocer que en el corriente año y en los años venideros, la reforma de pensiones implica un costo para el fisco, en la medida que las reservas del antiguo sistema se han agotado y el gobierno adquirió el compromiso de cumplir con sus obligaciones para con los pensionados. El Cuadro 13 muestra la carga fiscal en los próximos cinco años y plantea un reto para la gestión de las finanzas públicas en el país. Lo preocupante es que, hasta el momento, las autoridades se han esforzado poco por explicar cómo se va enfrentar este problema, el cual es perfectamente predecible.

Cuadro 13

Carga fiscal de la reforma de pensiones

\begin{tabular}{lrrrrr}
\hline Año & 2000 & 2001 & 2002 & 2003 & 2004 \\
Costo fiscal en millones de colones & 452 & 1000 & 1600 & 2303 & 3354 \\
\hline
\end{tabular}

Fuente: La Prensa Gráfica, "Las pensiones, una amenaza para el fisco", 12 de octubre de 1999. p. 34.

28. Francisco Novoa, "Actividad Bursátil”, Boletín Trimestral de la Bolsa de Valores, 27, 1999. 


\section{El desempeño fiscal en 1999}

En esta sección se aborda el desempeño de las linanzas públicas durante 1999 , con especial énfasis en lo acontecido en el segundo semestre de 1999. Para ubicarse en un contexto temporal más amplio, la Gráfica 13 muestra la evolución del délicit del Sector Público No Financiero (SPNF), como proporción del producto interno bruto, desde 1991 hasta 1999. Así, en la primera mitad de la década se da un proceso de ajuste fiscal, pasando el déficit del SPNF de 4.6 por ciento del PIB, en 1992, a 0.1 por ciento del PIB, en 1995. A partir de 1996, la política fiscal se vuelve más laxa, al grado que en 1999 se alcanza el déficit más alto desde 1993, como proporción del PIB. A lo largo de esta sección se trata de dilucidar por qué se va dando este deterioro en las finanzas públicas.

\section{Gráfica 13}

\section{Déficit fiscal del sector público no financiero (porcentaje del PIB)}

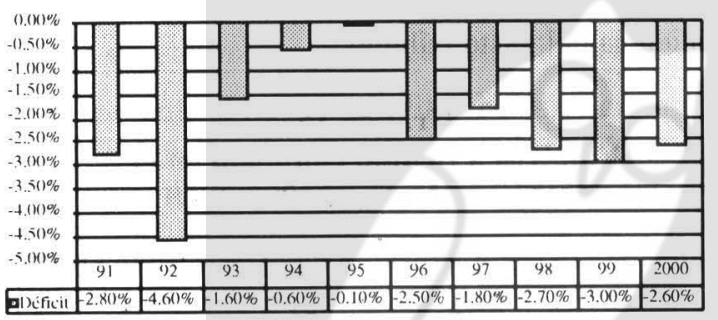

Fltente: Ministerio de Hacienda.

Nota: La cifra del año 2000 corresponde al estimado según el programa monetario y financiero del BCR.

La situación liscal durante 1999 estuvo influenciada por la reducida tasa de crecimiento real de la economía (cerca de 2.2 por ciento), por la evolución en el índice de precios (-1.0 por ciento), que representa una caída en el índice general, así como por otros fenómenos, tal como la aprobación tardía del presupuesto, en mayo de 1999, y la caída del precio de productos agrícolas de exportación, café y azúcar principalmente.

Al comparar las metas proyectadas para 1999 con el nivel de cumplimiento, así como con los resultados de 1998 (Cuadro 14), se evidencia el nivel de deterioro que experimentaron la mayoría de las variables, a nivel del Gobierno Central y del
Sector Público No Financiero. El Gobierno Central cerró en 1998 con un déficit fiscal de 2057 millones; la meta para 1999 era de 2211 y se elevó a 2338 millones, es decir en apenas un año creció en nada menos que 281 millones de colones. El ahorro corriente, que en 1998 fue del orden de los 824 millones, para 1999 se proyectó una meta de 931 millones de colones, pero en la realidad fue de apenas 86 millones de colones, y se redujo de forma significativa y afectó, por lo tanto, las posibilidades de inversión con recursos propios y, a la vez, presionó la tendencia al alza en el saldo de la deuda pública y del nivel del délicit fiscal. La recolección de impuestos en 1999 alcanzó los 11327 millones de colones, cifra superior en 583 millones de colones sobre lo recolectado en 1998, e inferior en 1321 respecto de la meta programada.

\section{Cuadro 14}

Metas del sector público y su cumplimiento en 1999

(En millones de colones)

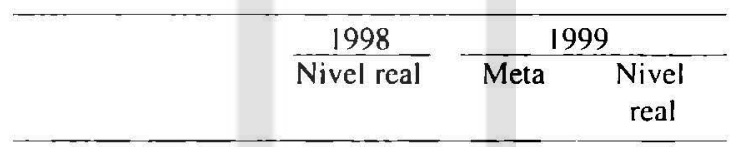

\section{GOES}

Monto déficit fiscal

\begin{tabular}{lrrr} 
(en millones) & $-2,057$ & $-2,211$ & $-2,338$ \\
Monto ahorro & 824 & 931 & 86 \\
Impuestos & 10,744 & 12,648 & 11,327 \\
Presión tributaria & 10.34 & 12.03 & 10.78 \\
SPNF & & & \\
Monto déficit & $-2,764$ & $-2,888$ & $-3,181$ \\
Monto ahorro corriente & 1,060 & 1,222 & 67 \\
Ingresos & 15,538 & 15,975 & 15,475 \\
Gastos totales & 18,458 & 18,630 & 18,940 \\
\hline
\end{tabular}

Fuente: BCR, "Programa Monetario 1999" y Página Web.

En lo que respecta a las cuentas del Sector Público No Financiero (SPNF), la situación también refleja un deterioro; el déficit es creciente, el ahorro decreciente, el nivel de ingresos también decrece, a diferencia del nivel de gastos que es creciente. De nueva cuenta se presenta una clara contradicción en el manejo de las finanzas públicas salvadoreñas; por un lado, la presión tributaria decrece y la presión del gasto aumenta. 
La Gráfica 14 muestra una de las tendencias más preocupantes que presentan las finanzas gubernamentales; por un lado, la presión del gasto sobre el producto interno bruto presenta una tendencia al alza, al menos de 1997 a 1999, y, por el otro, la presión tributaria se mantiene muy baja desde 1996, llegando apenas a 10.78 por ciento en 1999. Conforme pasan los años, la capacidad de recolección de impuestos no logra aumentar para satisfacer las demandas del gasto, situación que se explica por las siguientes causas: la desgravación arancelaria, el aumento en la evasión, el hecho de que los agentes económicos ante la situación de crisis se vuelven cautelosos en el pago de sus obligaciones tributarias, el aumento en la apropiación indebida en el caso del IVA, en que cada vez son menos noticia los casos de evasión, la dificultad jurídica de hacer que se ejerza la ley contra el delito de evasión fiscal, entre los principales.

\section{Gráfica 14}

\section{Presión tributaria y del gasto del SPNF} 1995-1999

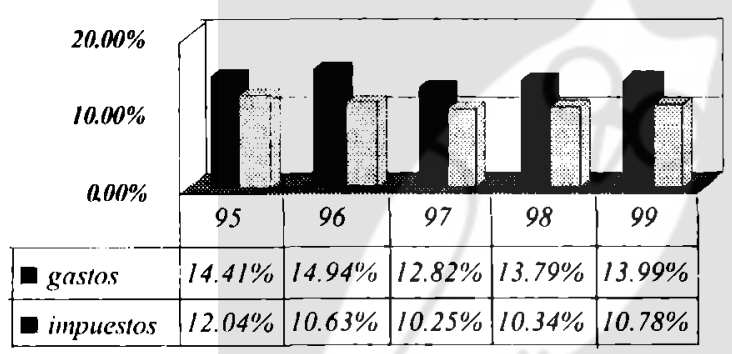

Fluente: Banco Central de Reserva.

Nota: Los impuestos para 1995 no han sido corregidos por la devolución del IVA.

Por otra parte, si la capacidad de recolección de impuestos presenta un claro estancamiento y la presión del gasto va en aumento, esto significa que, de manera efectiva, se está aplicando una reducción de la capacidad financiera del Estado. Al reducir la capacidad financiera del Estado, se está debilitando su capacidad para regular aquellos aspectos en que el mercado no funciona adecuadamente, dejando mayores oportunidades a la voracidad de la competencia. Por otro lado, hay una clara tendencia a que el gasto aumente, con lo cual se incrementa el aparato de Estado; por tanto, por el lado del gasto no existe la austeridad recomendada por las políticas neoliberales, mientras que por el lado de reducción de la carga impositiva sí existe un debilitamiento del Estado.

La combinación de ambas tendencias genera una presión para que el nivel del déficit fiscal tienda a aumentar y que el nivel de endeudamiento público también crezca, situaciones que generan cierta desestabilización en las cuentas del sector público.

La situación anterior se refuerza al considerar la evolución en el nivel de empleo que genera el Gobierno Central (Gráfica 15). En 1997, el nivel de empleo, según el presupuesto general, ascendió a 100567 puestos a tiempo completo; en 1998 se redujo a 99567 , y en los siguientes años el nivel creció hasta llegar a los 101253 puestos en el año 2000. Esto significa que se experimentó un incremento del orden de los 1686 puestos en dos años. No se está argumentando sobre el nivel óptimo de empleados en el sector público, sino que se está cuestionando que en un momento de deterioro de las finanzas públicas, el número de empleados tenga una tendencia hacia el alza, cuando los esfuerzos deberían estar orientados hacia la mejora de la eficiencia del gasto público.

\section{Gráfica 15}

\section{Empleos a tiempo completo en el} Gobierno Central 1997-2000

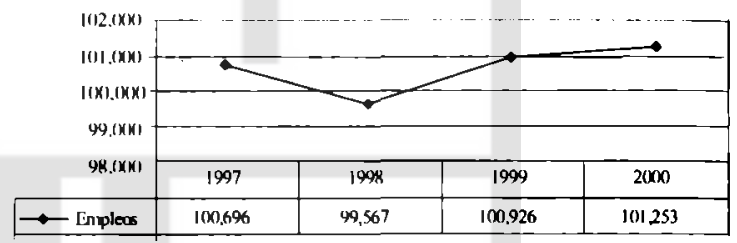

Fuente: Ministerio de Hacienda.

\subsection{El comportamiento fiscal en el segundo se- mestre de 1999}

Durante el segundo semestre de 1999, las cifras acumuladas presentaron en algunos casos diferencias notables (Cuadro 15). De las donaciones recibidas, el 87.57 por ciento se recibieron en el segundo semestre, al igual que el 64.71 por ciento de las transferencias de empresas públicas, que apenas llegaron a los 17 millones de colones. Así, en 1998 totalizaron 141 millones de colones. Mientras que de los ingresos de capital, que durante todo el año sumaron la ínfima cantidad de 5 
millones de colones, cl 80 por ciento se recibió durante el primer semestre.

Los impuestos tuvieron el comportamiento normal observado en los años anteriores, en el sentido de que durante el primer semestre se percibió una cantidad mayor, debido a que incluyó la fase del pago de las obligaciones de la renta, lo cual clevó la cantidad de ingresos tributarios. En el primer semestre se percibió el 57.08 por ciento de los impuestos.

Por el lado de los gastos la situación fue bastante parcja, ya que el 47.69 por ciento se gastó en el primer semestre y el restante 52.31 por ciento en el scgundo. Es muy importante destacar este dato, en el sentido de que la aprobación tardía del presupuesto no tuvo una incidencia clara en limitar los gastos durante el primer semestre que, como se recordará, se fusionó con el presupucsto de 1998. Lejos de ello, todo indica que el nivel de aclividades realizadas se desarrollaron sin contraliempos de carácter financiero.

En donde sí hay claras diferencias es en lo que se reliere a las cuentas de resultado, tanto por el lado del ahorro corriente como del déficit. En lodo el año se logró un monto de 86 millones de colones de ahorro, pero en el primer semestre se tenían acumulados 846 millones de colones, y en el segundo semestre se desacumularon un total de 760 millones de colones.

En lo que respecta al monto del déficit fiscal, durante todo el año se acumuló un total de 2338 millones de colones; en el primer semestre el monto ascendió a 203 millones de colones, y en el segundo a 2135 millones de colones. Se evidencia una clara diferencia en el comportamiento fiscal de ambos semestres; por un lado, durante el primero el nivel del déficit fue moderado, apenas llegó al 8.68 por ciento del total del año, esto a pesar de que el nivel del gasto total fue bastante balanceado en ambos semestres; mientras que en el segundo se disparó el nivel del déficit, ya que acumuló el 91.32 por ciento de lo registrado en todo el año. La explicación de este comportamiento pudiera ser el hecho de que durante el primer semestre no se contaba con que el presupuesto estuviera

aprodaao y en el segunao sı, so cual generaria una tendencia a restringir el gasto en el primero y a expandirlo en el segundo. Pero la evidencia de la información disponible indica que ello no aconteció así; como ya se indicara, hubo un balance en el monto del gasto realizado en ambos semestres, lo cual nos lleva a deducir que lo sucedido está íntimamente relacionado con el comportamiento de los ingresos corrientes y de capital, en el sentido de que durante el primer semestre su monto fue mayor respecto del segundo.

Para corroborar esta situación es conveniente apoyarse en los resultados de la cuenta del ahorro corriente que, como ya se señaló, durante el primer semestre arrojó un saldo positivo, lo cual es indicativo de que los ingresos corrientes fueron superiores a los gastos corrientes; mientras que en el segundo, se acumuló un desahorro de $760 \mathrm{mi}$ llones de colones. En este caso, los ingresos corrientes fueron inferiores al gasto corriente, lo cual provocó el nivel de pérdida del ahorro.

Los resultados financieros del segundo semestre contrastan con el discurso oficial de que se estaría operando con austeridad. Se debe recordar que en el momento en que tomó posesión la administración Flores, se hicieron públicas una serie de medidas que restringirían el nivel del gasto corriente: congelamiento de salarios, restricción de salarios, no compra de vehículos, reducción en el gasto de gasolina, no contratación de nuevo personal, etc., pero los datos indican que no hubo tal comportamiento en los gastos corrientes. 


\section{Cuadro 15 \\ Desempeño fiscal de 1999 por semestre \\ (cifras acumuladas por semestre en millones de colones y porcentajes)}

\begin{tabular}{lrrrrr}
\hline Concepto & $\begin{array}{r}\text { Jun/99 } \\
\text { Monto }\end{array}$ & $\%$ & $\begin{array}{r}\text { Dic/99/ } \\
\text { Monto }\end{array}$ & $\%$ & $\begin{array}{r}\text { Total } \\
\hline \text { 1. Tributarios }\end{array}$ \\
3.Transferencias de empresas públicas & 6,466 & $57.08 \%$ & 4,861 & $42.92 \%$ & 11,327 \\
$\quad$ B. Ingresos de capital & 4 & $35.29 \%$ & 11 & $64.71 \%$ & 17 \\
C. Donaciones & 22 & $80.00 \%$ & 1 & $20.00 \%$ & 5 \\
V. Superávit (déficit) global & & $12.43 \%$ & 155 & $87.57 \%$ & 177 \\
$\quad$ A. Incluyendo donaciones & $(203)$ & $8.68 \%$ & $(2,135)$ & $91.32 \%$ & $(2,338)$ \\
$\quad$ B. Excluyendo donaciones & $(225)$ & $8.95 \%$ & $(2,290)$ & $91.05 \%$ & $(2,515)$ \\
III.Ahorro.Corriente.(I.A-II.A) & 846 & $983.72 \%$ & $(760)$ & $-883.72 \%$ & 86 \\
II. Gastos y concesión neta de préstamos & 7,015 & $47.69 \%$ & 7,694 & $52.31 \%$ & 14,709 \\
\hline
\end{tabular}

Fuente: Banco Central de Reserva.

\subsection{Comparación de los presupuestos de 1999 y 2000}

Los últimos dos presupuestos que ha aprobado la Asamblea Legislativa — con una diferencia de 6 meses, el de 1999 fue aprobado en mayo y el del 2000 en noviembre- difieren poco.

Por el lado de los ingresos (Cuadro 16), el monto sube en I 145 millones de colones, que representan un incremento de 6.7 por ciento. La estructura tributaria es similar, con un claro predominio de los impuestos indirectos, muy cercanos al 70 por ciento. El IVA se constituye en la principal fuente impositiva con aproximadamente 55 por ciento de participación en los ingresos tributarios. La totalidad de ingresos corrientes representan entre 6 y 7 por ciento de los impuestos, mientras que la totalidad de ingresos se encuentran entre 132 y 135 por ciento de los ingresos tributarios.

A partir del comportamiento esperado en los impuestos para el 2000 , se puede deducir que las medidas de modificación impositivas que se adoptaron, a propuesta del ejecutivo -que incluyen una serie de modificaciones a la ley de renta y del IVA-, implican reducir las formas de elusión fiscal que anteriormente contenían sus respectivas leyes, pero cambiarían muy poco el comportamiento de los impuestos ${ }^{2 y}$.
El monto total de los ingresos en 1997 ascendió a 13680.3 millones de colones; en 1998 ascendió a 17837.0 millones de colones con un alza de 4156.7 millones de colones. En 1999 se presupuestaron 17079.3 millones de colones, es decir una caída de 757.7 millones de colones respecto de los realizado en el año anterior. Para el 2000 se espera una entrada total de 18224.3 millones de colones, es decir, un incremento de 1145.0 millones de colones.

Por el lado de la recolección total de impuestos, en 1997 entraron 10771.3 millones de colones; en 1998 se recogieron 11229.8 millones de colones; en 1999 se pronosticó una recolección de 12647.8 millones de colones, pero las cifras preliminares arrojaron un monto de 11237.0 millones de colones $^{310}$, es decir una reducción de 1410.8 millones de colones. Para el 2000 , el presupuesto contempla una suma de 13805.8 millones de colones, que implicarían un incremento de 2568.8 millones de colones por arriba de lo efectivamente recaudado en 1999, y un alza de $ф 1,1158$ sobre lo presupuestado.

En cualquiera de los casos, pareciera que las metas de incremento en la recaudación son demasiado optimistas y que contrastan con la realidad, máxime si se toma en cuenta que para el 2000 se

29. El listado de medidas aparece en el Departamento de Economía de la UCA, 1999, op. cir.

30. Banco Central de Reserva, 10 de febrero de 2000. 
espera una presión tributaria de 12.6 por ciento, que es superior en 1.9 por ciento a la realmente lograda en 1999. La meta de alcanzar una presión tributaria de 12.6 por ciento parece ser demasiada optimista y puede conducir a la generación de una mayor presión sobre el déficit fiscal, dado que los egresos presupuestarios se han hecho sobre la base de ingresos tributarios inflados. Si se toma en cuenta que, por lo general, los gastos casi por regla general se incrementan en el transcurso de un determinado ejercicio fiscal, producto de los refuerzos presupuestarios, y que los ingresos tributarios no han alcanzado los montos presupuestados, al menos durante los últimos cuatro años, la combinación de ambos elementos puede conducir a que se dispare el déficit en el 2000 , con el agravante de que ya no se dispondrá de los grandes contingentes de recursos provenientes de la privatización de empresas públicas y del traslado de excedentes financieros de dichas empresas.

\section{Cuadro 16}

Ingresos tributarios 1997-2000

(En millones de colones y porcentajes)

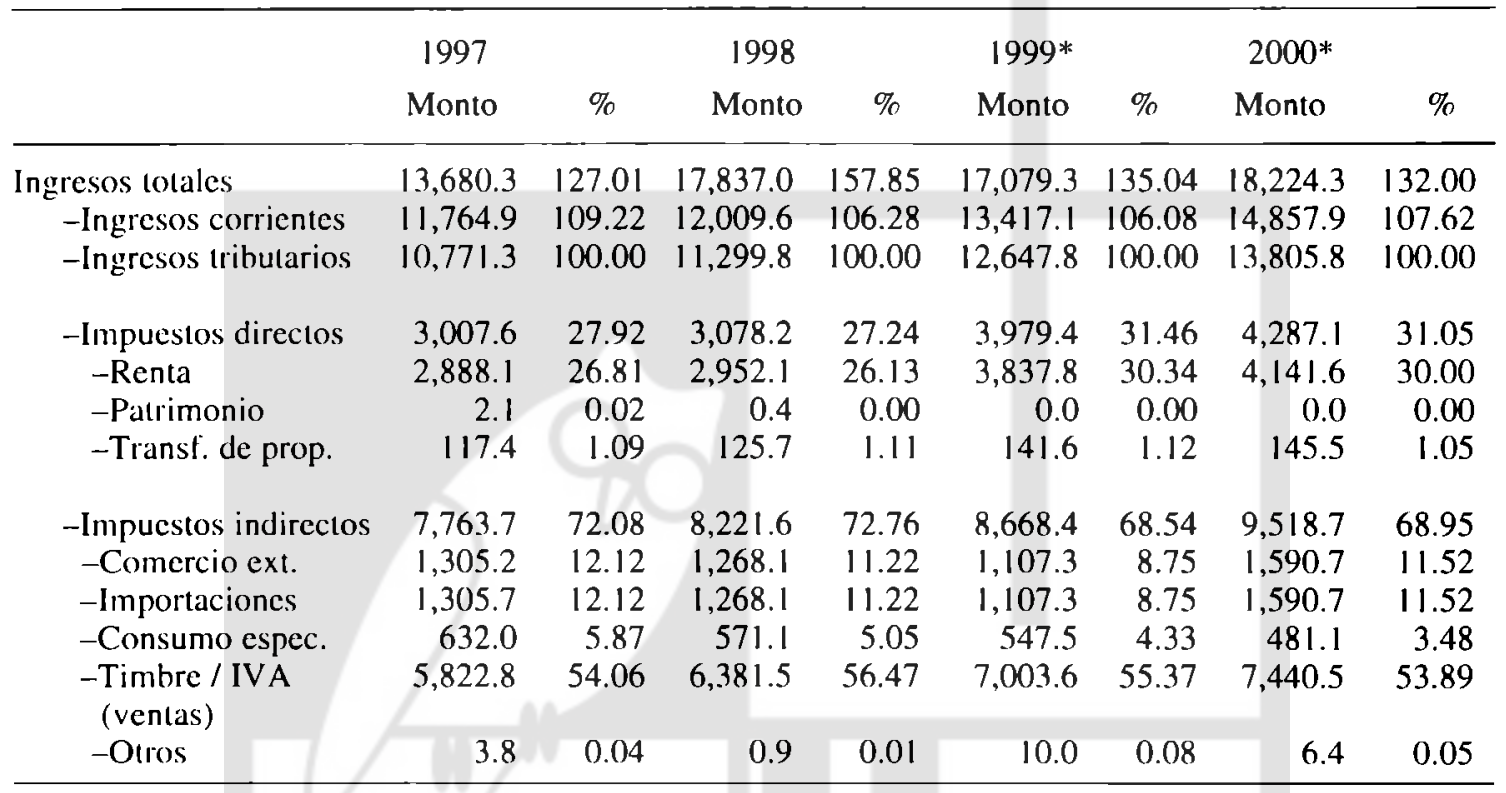

* Corresponden al presupuesto áprobado.

Fuente: Liquidación del presupuesto y presupuesto aprobado.

Por cl lado de los gastos (Cuadro 17), en 1997 se gastaron 14466.9 millones de colones. Por áreas de gestión, la de Desarrollo Social fue la que recibió una asignación mayor con 32.1 por ciento; en scgundo lugar fue la Deuda Pública con 18.0 por ciento; el tercer lugar le correspondió a la Administración de Justicia y Seguridad Pública con 15.) por ciento; el apoyo al Desarrollo Económico recibió el 14.4 por ciento, y la Conducción Administrativa el 12.5 por ciento. El presupuesto del 2000 tiene en primer lugar al Desarrollo Social con 37.2 por ciento; el segundo le corresponde a la Deuda Pública con 16.4 por ciento; el tercero a la Administración de Justicia y Seguridad Pública; luego la Conducción Administrativa con 12.6 por ciento, y el apoyo al Desarrollo Económico con 10.6 por ciento.

Sorprende lo que está aconteciendo en las áreas de gestión destinadas al Apoyo al Desarrollo Económico, ya que la suma presupuestada para el 2000 , que llega a los 1923.3 millones de colones, es la cifra más baja que ha recibido a partir de 
1997, lo cual es indicativo del menor interés en apoyar la reactivación económica de importante scctores productivos que se encuentran deprimidos que, en la práctica, han sido olvidados por las gestiones de los últimos gobiernos. Dentro de los sectores marginados sobresale el agropecuario.

Al comparar los presupuestos de 1999 y 2000 se mantiene la tendencia de aumentar la parte deslinada al Desarrollo Social y a la Deuda; de mantener la proporción destinada a Seguridad y Conducción Administrativa, y de reducir la de Apoyo al Desarrollo.

\section{El sector externo}

Esta sección aborda la situación reciente del sector externo de la economía salvadoreña desde una perspectiva de largo plazo. Así, se liene por objetivo interpretar la evolución del sector externo de los últimos seis meses, en el marco de un horizonte temporal más amplio. Adicionalmente, se tratan de destacar los principales cambios estructurales del sector externo de la economía en la década de los noventa y, a partir de estos, tratar de señalar cuáles son las perspectivas para el próximo año. En la primera parte se estudia la evolución de las exportaciones e importaciones de bienes, y el saldo de la balanza comercial. En la segunda parte se estudia la evolución de la balanza de cuenta corriente y se destaca la función preponderante que tienen las remesas familiares. En la tercera parte se estudia la evolución de la cuenta de capitales y de las reservas internacionales netas. Y en la cuarta parte se aborda la evolución de la deuda externa y la capacidad de endeudamiento del país.

Cuadro 17

Gasto por área de gestión y estructura, 1997-2000 (En millones de colones y porcentajes)

\begin{tabular}{|c|c|c|c|c|c|c|c|c|}
\hline & $\begin{array}{r}1997 \\
\text { Monto }\end{array}$ & $\%$ & $\begin{array}{c}1998 \\
\text { Monto }\end{array}$ & $\%$ & $\begin{array}{l}\text { 1999* } \\
\text { Monto }\end{array}$ & $\%$ & $\begin{array}{l}2000 * \\
\text { Monto }\end{array}$ & $\%$ \\
\hline Conducción Administrativa & $1,803.0$ & 12.5 & $2,121.9$ & 12.7 & $2,260.8$ & 13.2 & $2,291.9$ & 12.6 \\
\hline Adnón. Justicia y Seguridad & $2,176.1$ & 15.0 & $2,592.3$ & 15.5 & $2,864.1$ & 16.8 & $2,782.4$ & 15.3 \\
\hline Desarrollo Social & $4,646.3$ & 32.1 & $5,681.3$ & 33.9 & $6,186.4$ & 36.2 & $6,785.0$ & 37.2 \\
\hline Apoyo Desarrollo Económico & $2,079.7$ & 14.4 & $2,503.6$ & 14.9 & $1,816.4$ & 10.6 & $1,923.3$ & 10.6 \\
\hline Deuda Pública & $2,606.3$ & 18.0 & $2,620.5$ & 15.6 & $2,706.3$ & 15.8 & $2,983.1$ & 16.4 \\
\hline Obligaciones Generales & $1,155.5$ & 8.0 & $1,084.9$ & 6.5 & $1,199.3$ & 7.0 & $1,281.0$ & 7.0 \\
\hline Producción empresarial & & 0.0 & 166.9 & 1.0 & 46.0 & 0.3 & 177.7 & 1.0 \\
\hline
\end{tabular}

* Corresponde a lo presentado en el respectivo presupuesto.

Fuente: Ministerio da Hacienda. "Informe de la Gestión Financiera del Estado. Ejercicio Fiscal 1996".

\subsection{Balanza comercial}

Antes de abordar el análisis de las exportaciones de bienes y servicios en los últimos seis meses, se tratan de describir los principales cambios estructurales en la evolución de la balanza comercial de bienes a lo largo de la década de los noventa (Cuadro 8).

(1) Al finalizar 1999, la economía salvadoreña es una economía mucho más abierta que al comienzo de los noventa. En 1991, el porcentaje de la exportaciones más las importaciones sobre el producto interno bruto era de 42.1 por ciento, mientras que al final de la década dicho porcentaje alcanzaba un 54.8 por ciento. Esto es resultado de una política de liberalización del comercio exterior, que se refleja en la desgravación arancelaria a lo largo de la década, y un esfuerzo en la promoción de exportaciones no tradicionales, con la política de la devolución del $6 \%$ a las exportaciones no tradicionales, la apertura a la inversión extranjera, y la promoción las zonas francas y los recin- 
tos fiscales, que han favorecido la industria de la maquila.

(2) La estructura de las exportaciones ha cambiado drásticamente en favor de las exportaciones no tradicionales y de las exportaciones de maquila, aunque las exportaciones tradicionales han mostrado cierto crecimiento a lo largo de la década de los noventa. Para estudiar la evolución de la estructura de las exportaciones, se toman como cifras base las exportaciones totales menos las importaciones de maquila, es decir que al sector maquila no se le contabiliza a partir de las exportaciones brutas, ya que tienen un fuerte componente importado; en tal sentido, lo que estamos considerando son las exportaciones netas de la maquila ${ }^{31}$.

\section{Cuadro 18}

Balanza comercial de bienes

(En millones de dólares)

\begin{tabular}{lrrrrrr}
\hline & 1994 & 1995 & 1996 & 1997 & 1998 & \multicolumn{1}{c}{$1999 / 1$} \\
\hline Exportaciones FOB & $I, 652$ & $I, 788$ & 1,789 & 2,416 & 2,446 & 2,497 \\
Tradicionales & 324 & 426 & 414 & 604 & 421 & 316 \\
$\quad$ Café & 271 & 362 & 339 & 518 & 322 & 244 \\
$\quad$ Azúcar & 30 & 38 & 37 & 56 & 66 & 46 \\
$\quad$ Camarón & 23 & 26 & 39 & 30 & 33 & 25 \\
No tradicionales & 495 & 580 & 610 & 755 & 836 & 848 \\
$\quad$ Centroamérica & 340 & 427 & 455 & 576 & 613 & 621 \\
$\quad$ Resto del mundo & 155 & 152 & 155 & 179 & 223 & 228 \\
Maquila & 430 & 647 & 765 & 1,057 & 1,189 & 1,333 \\
Importaciones CIF & 2575 & 3,329 & 3,222 & 3,739 & 3,960 & 4,084 \\
Bienes de consumo & 598 & 802 & 792 & 918 & 929 & 1,012 \\
Bienes intermedios & 988 & 1,211 & 1,207 & 1,311 & 1,355 & 1,300 \\
Bienes de capital & 666 & 843 & 672 & 745 & 826 & 817 \\
Maquila & 322 & 473 & 551 & 766 & 850 & 955 \\
Saldo & $-1,326$ & $-1,677$ & $-1,433$ & $-1,323$ & $-1,5 / 3$ & $-1,587$ \\
\hline
\end{tabular}

1/ Cifras preliminares.

Fuente: Banco Central de Reserva.

Tomando esto en cuenta, la participación de las exportaciones tradicionales en las exportaciones totales cae de 44.3 por ciento, en 1991, a 20.5 por ciento, en 1999. Sin embargo, éstas siguen manteniendo una participación importante. Adicionalmente, a lo largo de la década de los noventa, el crecimiento de las exportaciones tradicionales ha sido positivo, ya que en 1991 alcanzaban los 272.1 millones de dólares, mientras que en 1999 llegaban a 316 millones de dólares. Sin embargo, existe una fuerte volatilidad en el valor de las exportaciones tradicionales, por las fluctuacio- nes en los precios internacionales de los productos agrícolas, principalmente los del café y el azúcar.

Por otra parte, las exportaciones no tradicionales han experimentado un fuerte crecimiento, aumentando su participación de 51.4 por ciento, en 1991, a 55 por ciento, en 1999. Este aumento es aún más sorprendente si se observa el valor de dichas exportaciones, que pasaron de 315.9 millones de dólares, en 1991, a 848 millones de dólares, en 1999; es decir, un aumento de 268 por ciento en nueve años. Este incremento en la participación de las exportaciones no tradicionales en el total de las

31. Si no se hace este ajuste, entonces el sector maquila aparece sobredimensionado y el resto de sectores aparece subvaluado. Por el contrario, al hacer el ajuste, el sector maquila está siendo castigado; sin embargo, como las cifras lo demuestran, su participación es considerablemente alta. 
exportaciones se debe, en primer lugar, al dinamismo de las exportaciones no tradicionales hacia el resto de países centroamericanos, cuyo valor se triplicó en el período considerado, y, en segundo lugar, a un crecimiento positivo de las exportaciones no tradicionales fuera de Centroamérica, que si bien han crecido, no alcanzaron a duplicarse. Este fenómeno refleja dos cosas: por un lado, el esfuerzo que ha hecho cl país por diversificar sus exportaciones y, por cl otro, la importancia que tiene para El Salvador el mercado Centroamericano.
Finalmente, el auge exportador de los noventa se ve impulsado fuertemente por el crecimiento de las exportaciones de maquila. Su partición, en términos de exportaciones netas de maquila, pasó de 4.3 por ciento a inicios de la década, en 1991, a 24.5 por ciento, en 1999. En términos de valor, las exportaciones netas de maquila pasaron de 26.44 millones de dólares, en 1991, a 378 millones de dólares en 1999, es decir un incremento de \% 1542.8.

\section{Gráfica 16 \\ Relación exportaciones/importaciones \\ y su tendencia \\ (en porcentaje)}

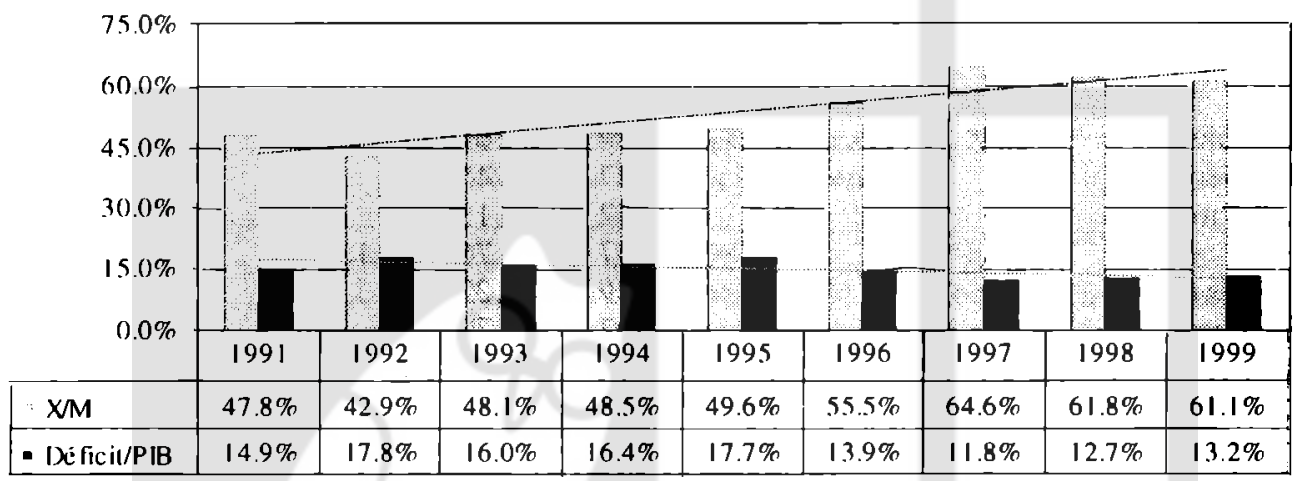

(3) La brecha comercial ha crecido continuamente y es reflejo de un serio desequilibrio estructural; sin cmbargo, en términos relativos muestra una tendencia hacia la mejoría. En términos de valor en dólares, el déficit de la balanza comercial de bienes pasó de 791.5 millones de dólares, en 1991, a 1587 millones de dólares, en 1999, lo cual se dche a dos factores de carácter estructural: en primer lugar, es muestra de una debilidad en el aparato productivo salvadoreño, que depende fuertemente de insumos intermedios y capital importado, y carece de integración entre los diferentes sectores productivos; y en segundo lugar, se explica en gran parte por el flujo de remesas familiares provenientes de los salvadoreños residentes en el extranjero, que ha permitido sostener dicha brecha comercial sin hacer un ajuste en la demanda agregada. A pesar de este deterioro en valores absolutos de la cuenta de la balanza comercial, la economía ha mostrado cierta reducción en la vulnerabi- lidad externa, aunque ésta sigue siendo alta como porcentaje del produclo interno bruto. Por ejemplo, en 1991, las exportaciones salvadoreñas apenas alcanzaban a financiar un $\mathbf{4 7 . 8}$ por ciento de las importaciones, mientras que en 1999 alcanzaron a financiar el 61.1 por ciento. Es más, si se obtiene una tendencia lineal de la relación entre exportaciones e importaciones a lo largo del período considerado, ésta muestra una tendencia negativa, lo cual es resultado del esfuerzo que el país ha realizado para promover las exportaciones (Gráfica 16). No obstante esta leve mejoría, el déficit de la balanza comercial como proporción del PIB fue de 14.9 por ciento, en 1991, y llegó a 13.2 por ciento, en 1999. Esta cifra es extremadamente alta, y la línea de tendencia a lo largo de la década, si bien es decreciente, no muestra señales claras de una mejoría significativa, lo cual indica que el país necesita un esfuerzo exportador todavía mayor que el de la década de los noventa. 
Dentro de este conjunto de cambios estructurales a lo largo de la década de los noventa, se puede hacer un análisis más detallado de la evolución de las exportaciones y las importaciones durante el segundo semestre de 1999 (Cuadro 18). En relación con las exportaciones, 1999 culminó con apenas un crecimiento de 2.1 por ciento. Esto se explica, en gran parte, por la fuerte caída en los precios internacionales del café, ocasionando que el valor de las exportaciones de café se mantuviera por debajo de lo logrado en 1998 y 1997. Sin embargo, durante el segundo semestre, a pesar de que los precios siguieron cayendo hasta el mes de octubre, las exportaciones de café se mantuvieron similares al segundo semestre de 1998; por tanto, la caída en las exportaciones de este rubro se realizó principalmente en el primer semestre de 1999. A partir de noviembre los precios del café han comenzado a recuperarse $y$, por ende, las exportaciones del rubro aumentaron en diciembre de 1999 (21 millones de dólares), en comparación con diciembre de 1998 (11.7 millones de dólares). De mantenerse el precio actual en los precios del café, se esperaría que las exportaciones se recuperaran levemente en los próximos meses.

Por su parte, las exportaciones de productos no tradicionales, que habían crecido aceleradamente a lo largo de la década, mostraron una fuerte reducción en su dinamismo, creciendo únicamente a 1.4 por ciento en 1999. Este menor dinamismo se explica tanto en las exportaciones no tradicionales hacia Centroamérica, como hacia fuera de la región, que crecicron a 1.3 y 2.2 por ciento, respectivamente. Es de esperarse que en los próximos meses exista una recuperación de dichas exportaciones, ya que se espera que Centroamérica, en su conjunto, tenga un crecimiento mayor, al igual que el resto de América Latina.

De igual forma, el crecimiento de las exportaciones de maquila fue menor en 1999 que en 1998 -12.1 y 12.5 por ciento, respectivamente-. El crecimiento de la maquila, si bien es mucho más alıo que el de los otros sectores, refleja una fuerte disminución en relación con el período 1991 . 1997, cuando creció a una tasa promedio anual de
41 por ciento. Al igual que en el caso del crecimiento sectorial, el sector que más le ha impregnado dinamismo a las exportaciones es el sector que, a la vez, muestra una tendencia hacia la baja en el crecimiento. Esto nos está indicando que las posibilidades de expansión de dicho sector están llegando a sus límites bajo las condiciones actuales de acceso al mercado de Estados Unidos, que es hacia donde se dirigen las exportaciones de maquila.

En tal sentido, se esperaría que exista un incremento mayor en las exportaciones de maquila, únicamente si cambian las concesiones comerciales que Estados Unidos otorga al país bajo el esquema de la Iniciativa de la Cuenca del Caribe (ICC). Actualmente, los beneficios de la ICC no se aplican a productos como calzado, guantes de trabajo, atún preparado o conservado en contenedores herméticos, petróleo o sus derivados, relojes de pulsera y sus partes, prendas textiles, bolsos y artículos de viaje. Sin embargo, en 1990 hubo una enmienda que extendía los beneficios a productos textiles que son elaborados con tela cortada y tejida en Estados Unidos. Actualmente se está contemplando la ampliación de las concesiones comerciales de la ICC entre el Congreso - propuesta Crane - y el Senado - propuesta Roth-Brouxnorteamericanos, donde las mayores ampliaciones se encuentran en la versión del Congreso, ya que permitiría incluir entre los productos beneficiados las prendas de vestir fabricadas con tela producida en la región. Hasta la fecha, aún no se ha determinado cuál de las dos propuestas será ratificada pero, en todo caso, esto vendrá a favorecer al sector, por lo que se espera que las exportaciones de maquila sigan aportando mayores fuentes de empleo y de divisas para el país. Para un país como El Salvador, dichas ampliaciones pueden ser importantes, ya que, por ejemplo, en 1998 las exportaciones totales a Estados Unidos llegaban a I 436 millones de dólares, de los cuales el 81.5 por ciento correspondía a productos textiles y, por tanto, no se beneficiaban completamente del trato preferencial $^{32}$.

32. J. C. Deras Robles y M. M. Durán Tobar, "El Salvador: exportaciones dentro del programa de recuperación económica de la cuenca del caribe 1994-1999", Boletín Económico, 133, Banco Central de Reserva, noviembre, 1999. 


\section{Cuadro 19 \\ Remesas familiares y saldo en cuenta corriente y de capital}

(En millones de dólares)

\begin{tabular}{ccccccc} 
& $\begin{array}{l}\text { Remesas de } \\
\text { los trabaja- } \\
\text { dores }\end{array}$ & $\begin{array}{l}\text { Remesas/P. } \\
\text { IB }\end{array}$ & $\begin{array}{l}\text { Saldo en } \\
\text { cuenta } \\
\text { corriente }\end{array}$ & $\begin{array}{l}\text { Saldo en } \\
\text { CC/PIB }\end{array}$ & $\begin{array}{l}\text { Saldo en } \\
\text { cuenta de } \\
\text { capital y } \\
\text { financiera }\end{array}$ & $\begin{array}{l}\text { Saldo en } \\
\text { CC/PIB }\end{array}$ \\
\hline 1992 & 857 & $14.4 \%$ & -151.6 & $-2.5 \%$ & 211.4 & $3.6 \%$ \\
1993 & 864 & $12.5 \%$ & -82.0 & $-1.2 \%$ & 251.5 & $3.6 \%$ \\
1994 & 964 & $11.9 \%$ & -17.9 & $-0.2 \%$ & 161.0 & $2.0 \%$ \\
1995 & 1,061 & $11.2 \%$ & -261.6 & $-2.8 \%$ & 408.2 & $4.3 \%$ \\
1996 & 1,087 & $10.5 \%$ & -169.1 & $-1.6 \%$ & 334.0 & $3.2 \%$ \\
1997 & 1,199 & $10.7 \%$ & 96.1 & $0.9 \%$ & 266.5 & $2.4 \%$ \\
1998 & 1,338 & $11.3 \%$ & -82.6 & $-0.7 \%$ & 385.8 & $3.3 \%$ \\
1999 & 1,350 & $11.2 \%$ & $-187.9 *$ & $-1.6 \% *$ & $87.6 *$ & $0.7 \% *$ \\
\hline
\end{tabular}

Fulente: Elaboración propia en hase a información del BCR.

Tipo de cambio: US $\$ 1=8.37,1992$. US $\$ 1=8.70,1993$. US $\$ 1=8.75,1994-1999$.

"Corresponde al mes de septiembre.

En conclusión, dada la difícil coyuntura internacional, las exportaciones en 1999 apenas lograron crecer un 2.1 por ciento, y debido a la mejora en los precios internacionales del café, a la posible reaclivación de las economías centroamericanas, y con la aprobación de cualquiera de las dos versiones de ampliación de la ICC $^{3 .}$, se espera que las exportaciones experimenten un crecimiento mayor en el año 2000. Sin embargo, no se espera que en el año 2000 las tasas de crecimiento de las exportaciones lleguen a ser tan altas como en el período 1992-1997, en que promediaron un 22.7 por ciento y, por ende, muy difícilmente se convertirán en una motor de crecimiento acelerado en el corto plazo.

\subsection{La balanza de cuenta corriente}

Como ha ocurrido a lo largo de la década de los noventa, la brecha en la balanza comercial logra compensarse y explicarse, en gran parte, por el

flujo de las remesas familiares de los salvadoreños que viven en el extranjero, principalmente en Estados Unidos. El Cuadro 19 presenta la evolución de las remesas familiares y el saldo en cuenta corriente desde 1992 hasta 1999, y su respectiva cifra como proporción del PIB. En promedio, para dicho período, las remesas familiares han representado un 11.7 por ciento del producto interno bruto, y para 1999 representaron el 11.2 por ciento. Así, tenemos que las remesas familiares han sido la palanca de la economía salvadoreña en la década de los noventa. No sólo han ayudado a mantener la estabilidad macroeconómica, sino que también han significado un mayor bienestar económico para las familias que las reciben, en tanto que aumentan sus ingresos $\mathrm{y}$, por consiguiente, contribuyen al alivio de la pobreza; en tal sentido, también han servido de válvula de escape de tensiones sociales.

Por su parte, el saldo de la balanza de cuenta corriente se ha mantenido a niveles manejables a

33. Las modificaciones a la ICC se encuentran actualmente en la fase de conferencia, lo que sucede cuando las dos cámaras legislativas de Estados Unidos, el Congreso y el Senado aprueban versiones distintas de una misma ley. Para el caso en cuestión, la versión menos favorable para Centroamérica y el Caribe es la del Senado, que únicamente extiende la ICC para permitir las exportaciones de ropa centroamericana fabricada con tela e hilo hechos en Estados Unidos, con un arancel de cero. Además, la versión del Congreso permitiría la exportación, con cero arancel, de ropa confeccionada con tela e hilos producidos en Centroamérica o el Caribe. 
lo largo de la década, con lo cual se ha obtenido un déficil promedio de 1.2 por ciento; inclusive, en 1997, cuando los precios del café fueron extraordinariamente elevados, se logró un superávit de cuenta corriente.

A septiembre de 1999, el déficit de la balanza de cuenta corriente era de 187.9 millones de dólares, lo cual representó el 1.6 por ciento del producto interno bruto; de tal manera que si se le compara con el año anterior, este año existe un leve deterioro en la cuentas externas ${ }^{34}$. En lo que se reliere a las transferencias corrientes al Gobierno Gencral, la cuenta corriente al mes de septiembre de 1999 refleja un saldo positivo de 17.9 millones de dólares, mientras que en diciembre de 1998 terminó con un saldo posilivo de 31 millones de dólares. Esto cstá indicando la tendencia, a lo largo de la década, hacia la disminución de las donaciones que el gobierno recibe, en comparación con la ayuda que recibió tras los acuerdos de paz.

Ante una posible mejoría en el déficit de la balanza comercial como proporción del producto interno bruto en el año 2000, y con el mantenimiento de las remesas familiares, se esperaría que el déficit de cuenta corriente como proporción del PIB se mantenga a niveles similares a los del presente año.

\subsection{La balanza de cuenta de capital y financie- ra}

La balanza de cuenta de capital y financiera, al contrario de la balanza en cuenta corriente, ha mantenido saldos positivos a lo largo de la década: un promedio de 3.2 por ciento del producto interno bruto, lo que ha permitido una acumulación de reservas internacionales netas (RIN). Estos saldos positivos en la cuenta de capital y financiera son el resultado de la entrada neta de inversión directa o inversiones de cartera, créditos comerciales y el endeudamiento externo de los sectores público y privado, pero principalmente el sector público. Hasta septiembre de 1999, llama la atención que, a diferencia de años anteriores, el saldo en la cuenta de capital y financiera es mucho menor, de 87.6 millones de dólares, y representa el 0.7 por ciento del PIB (Cuadro 20). Es importante señalar que dicho saldo probablemente no se hubiera logrado, ya que en el tercer trimestre de 1999, el saldo neto de préstamos del exterior fue de $\$-211.5$, es decir que en este período el país canceló préstamos por un monto mayor de los préstamos recibidos. De no haber sido por la inversión extranjera directa $y$ otras inversiones de cartera, que en conjunto lograron un saldo positivo de 243.5 millones de dólares, no se hubiera logrado el saldo positivo en la cuenta de capital y financiera. El saldo positivo en lo que son Inversiones Directas se debió a la privatización de las plantas térmicas y a la colocación de bonos del gobierno en los mercados internacionales.

En su conjunto, en la medida en que las entradas de capital superan el déficit en la cuenta corriente, el país puede incrementar el nivel de reservas internacionales netas (RIN). Así tenemos que, a lo largo de la década de los noventa, el Banco Central de Reserva ha sido un comprador neto de divisas. En el Cuadro 21 se observa el nivel de las RIN, que hasta diciembre de 1999 alcanzaban los 1969 millones de dólares, más del doble del nivel de diciembre de 1995. Las RIN crecieron en el período $1996-1998$ a un promedio de 23.8 por ciento anual. Sin embargo, para terminar 1999 se ha crecido a 11.54 por ciento. El aumento de las RIN es considerable, ya que en términos de meses de importaciones han crecido año con año, desde

34. Al momento de esta publicación sólo se dispone de información sobre la balanza de pagos hasta el mes de septiembre de 1999, y los datos del cuarto trimestre serán publicados por el Banco Central de Reserva hasta el 31 de marzo de 2000, por lo cual el resto de esta sección limita el estudio hasta el tercer trimestre de 1999. 
4.9 meses de importaciones en diciembre de 1996, hasta 6.9 meses en noviembre de 1999. De igual manera, al 30 de noviembre de 1999, las RIN representan un 483.9 por ciento del numerario en manos del público, y un 118.6 por ciento de la base monetaria. Estas cifras sobre las RIN le dan a El Salvador un grado de solvencia externa bastante elevada, al punto que las calificadoras internacionales de riesgo le dan a El Salvador excelentes calificaciones.

\section{Cuadro 20}

Balanza de pagos 1/

(En millones de dólares)

\section{CONCEPTO}

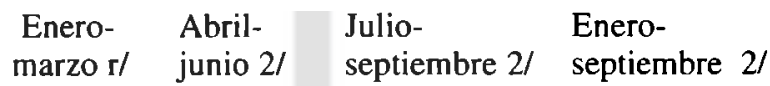

\section{Cuenta corriente}

I. Bienes y servicios

A. Bienes FOB

B. Servicios

II. Renta

1. Remuneración de empleados

2. Renta de la inversión

III. Transferencias corrientes

1. Gobierno general

2. Otros sectores

Remesas de trabajadores

Cuenta de capital y financiera

I. Cuenta de capital

1. Transferencia de capital Gobierno general Otros sectores

II. Cuenta financiera

A. Activos

1. Inversión directa en el exterior

2. Inversión de cartera

3. Otra inversión

Créditos comerciales

Préstamos

Moneda y depósitos

Otros activos

B. Pasivos

1. Inversión directa

2. Inversión de cartera

3. Otra inversión

Créditos comerciales

Préstamos

Moneda y depósito

Otros pasivos

C. Activos de reserva

Errores y omisiones

Total

\begin{tabular}{rrrr}
-70.5 & -54.6 & -62.8 & -187.9 \\
-343.9 & -392.1 & -397.7 & -1.133 .7 \\
-279.1 & -330.8 & -397.7 & -965.9 \\
-64.8 & -61.3 & -41.7 & -167.8 \\
-91.1 & -56.8 & -46.4 & -194.3 \\
1.2 & 0.5 & -0.3 & 1.4 \\
-92.3 & -57.3 & -46.1 & -195.7 \\
364.5 & 394.3 & 381.3 & 1140.1 \\
\hline 5.2 & 8.5 & 4.2 & 17.9 \\
359.3 & 385.8 & 377.1 & 1122.2 \\
316.9 & 345.9 & 332 & 997.3 \\
127.1 & 43.5 & -83 & 87.6 \\
21.5 & 6 & 8.2 & 35.7 \\
21.5 & 6 & 8.2 & 35.7 \\
18.7 & 0.9 & 1.2 & 20.8 \\
2.8 & 5.1 & 7 & 14.9 \\
105.6 & 37.5 & -91.2 & 51.9 \\
-108.5 & -12.9 & -12.4 & -133.8 \\
2 & -1 & -2 & -1 \\
0 & 0 & -1.6 & -1.6 \\
-110.5 & -11.9 & -8.8 & -131.2 \\
-76.9 & -6.7 & -17.7 & -101.3 \\
0 & 0.1 & -4.3 & -4.2 \\
-34.1 & -19.4 & 16.5 & -37 \\
0.5 & 14.1 & -3.3 & 11.3 \\
282.1 & 86.2 & 39.9 & 408.2 \\
17.8 & 12.8 & 147.4 & 178 \\
16.7 & -11.1 & 96.1 & 101.7 \\
247.6 & 84.5 & -203.6 & 128.5 \\
142.3 & 45.4 & 16.2 & 203.9 \\
123.5 & 32.8 & -211.5 & -55.2 \\
-18.2 & 6.3 & -8.3 & -20.2 \\
0 & 0 & 0 & 0 \\
-68 & -35.8 & -118.7 & -222.5 \\
-56.6 & 11.1 & 145.8 & 100.4 \\
0 & 0 & 0 & 0 \\
\hline & 6 & & \\
\hline
\end{tabular}

I/ Con la presentación de la Balanza de Pagos en base al V Manual del FMI, se da cumplimiento a los requerimientos establecidos en las Normas Especiales de Divulgación de Datos (NEDD) del FMI.

2/ Cifras preliminares; $\mathbf{r} /$ Cifras revisadas

Fuente: Banco Central de Reserva. 


\section{Cuadro 21 \\ Resevas internacionales netas \\ (En millones de dólares y porcentajes)}

\begin{tabular}{lrrrrr}
\hline & RIN & $\begin{array}{c}\text { Meses de } \\
\text { importa- } \\
\text { ción }\end{array}$ & $\begin{array}{c}\text { RIN/ } \\
\text { numerario } \\
\text { público }\end{array}$ & $\begin{array}{c}\text { RIN/base } \\
\text { monetaria }\end{array}$ & $\begin{array}{c}\text { Crecimiento } \\
\text { anual }\end{array}$ \\
\hline Dic-95 & 934.6 & & & & \\
Dic-96 & $1,099.5$ & 4.9 & 297.6 & 77.52 & $17.64 \%$ \\
Dic-97 & $1,462.1$ & 6.2 & 366.5 & 94.1 & $32.98 \%$ \\
Dis-98 & $1,765.3$ & 6.7 & 438.5 & 107.9 & $20.74 \%$ \\
Ene-99 & $1,782.5$ & 6.4 & 473.9 & 107.4 & $21.42 \%$ \\
Feb-99 & $1,770.6$ & 6.3 & 472.3 & 108.1 & $-2.53 \%$ \\
Mar-99 & $1,833.3$ & 6.6 & 472.6 & 109.5 & $-1.39 \%$ \\
Abr-99 & $1,834.2$ & 6.6 & 490.8 & 109.4 & $-2.14 \%$ \\
May-99 & $1,866.2$ & 6.7 & 512 & 113.4 & $7.84 \%$ \\
Jun-99 & $1,869.1$ & 6.7 & 531.5 & 113.2 & $13.44 \%$ \\
Jul-99 & $1,862.5$ & 6.7 & 531.5 & 113.2 & $16.21 \%$ \\
Ago-99 & $1,974.2$ & 7.1 & 535.1 & 120.2 & $22.90 \%$ \\
Sep-99 & $1,987.8$ & 7.1 & 561.5 & 122.7 & $9.99 \%$ \\
Oct-99 & $1,910.0$ & 6.8 & 512.3 & 118 & $11.01 \%$ \\
Nov-99 & $1,917.3$ & 6.9 & 483.9 & 118.6 & $10.88 \%$ \\
Dic-99 & $1,969.0$ & & & & $11.54 \%$ \\
\hline
\end{tabular}

Fuente: Banco Central de Reserva.

\subsection{La deuda externa}

Desde 1995 hasta 1999, la deuda externa pública aumentó en 29 por ciento, llegando a 2810 millones de dólares, lo cual representa un 23.1 por ciento del producto interno brutọ. En su mayoría, la deuda externa pública corresponde a la deuda del Sector Público, en segundo lugar a las empresas autónomas, y en menor medida a la deuda externa del Banco Central de Reserva. Si bien a lo largo de estos cinco años el aumento en valor es considerable, en términos relativos se ha mantenido estable en alrededor del 23.3 por ciento del PIB. En su mayor parte, la deuda externa pública corresponde a deuda de mediano plazo, 96.8 por ciento en 1999, lo que indica cierto grado de prudencia por parte de los dos últimos gobiernos en cuanto al endeudamiento externo. El servicio de la deuda, es decir los pagos de intereses y amortizaciones, fue de 549 millones en 1999, lo cual representa el 21.8 por ciento de las exportaciones de bienes. Si detenemos nuestro análisis hasta este punto, daría la impresión que la situación de la deuda externa de El Salvador es bastante manejable; sin embargo, si consideramos que 549 millones de dólares estaban comprometidos este año y se los restamos a las exportaciones de bienes, nos queda que el remanente apenas logra financiar el 47.7 por ciento de las imporlaciones. Es decir, sumando importaciones, más servicio de la deuda, el país es incapaz de pagar con sus propios medios las obligaciones internacionales. Este déficit se está pagando con las remesas familiares, con ingreso de divisas por inversión extranjera y con mayor endeudamiento. El país tiene capacidad para mantener este esquema pero, ¿hasta cuándo será capaz de financiar sus obligaciones externas con sus propios medios?

\section{Reflexiones finales}

La idea de los análisis de coyuntura económica es hacer un diagnóstico de la situación económica y distinguir entre los fenómenos de largo plazo y 
de corto plazo que corresponden al período analizado. En tal sentido, se trata de entender dónde cstamos y adónde vamos; por lo tanto, se busca hacer un pronóstico y un comentario sobre lo que se espera en el 2000.

\section{Cuadro 22}

Saldo de la deuda externa pública

(En millones de dólares)

\begin{tabular}{|c|c|c|c|c|c|}
\hline & $\mathrm{dic} / 95$ & $\mathrm{dic} / 96$ & $\mathrm{dic} / 97$ & dici-98 & $\mathrm{dic} / 991 /$ \\
\hline \multicolumn{6}{|l|}{ 1. Por deudor } \\
\hline Sector Público & $1,977.1$ & $2,276.6$ & $2,451.9$ & $2,466.7$ & 2,650 \\
\hline Gobierno Central2/ & $1,575.5$ & $1,828.9$ & $1,966.0$ & $2,005.0$ & 2,273 \\
\hline Autónomas & 401.6 & 447.7 & 485.9 & 461.7 & 377 \\
\hline Banco Central & 191.4 & 240.9 & 237.5 & 165.4 & 160 \\
\hline Total & $2,168.5$ & $2,517.5$ & $2,689.4$ & $2,632.1$ & 2,810 \\
\hline \multicolumn{6}{|l|}{ 1I. Por acreedor } \\
\hline Organismos bilaterales & 588.0 & 614.3 & 630.2 & 672.5 & 678 \\
\hline Organismos multilaterales & $1,455.1$ & $1,710.0$ & $1,774.3$ & $1,900.1$ & 1,870 \\
\hline Instituciones financieras & 125.4 & 193.1 & 284.9 & 59.8 & 262 \\
\hline \multicolumn{6}{|l|}{ III. Por plazo } \\
\hline Corto plazo &.-- & 156.5 & 272.5 & 131.7 & 91 \\
\hline Gobiemo Central & $\because-$ & 156.5 & 272.5 & 131.7 & 89 \\
\hline Autónomas & $\because-$ &.-- & $-\because-$ &.-- & 2 \\
\hline Banco Central & &.-- &.-- &.-- & - \\
\hline Mediano plazo & $2,168.5$ & $2,360.9$ & $2,416.9$ & $2,500.4$ & 2,719 \\
\hline Gobiemo Central & $1,575.5$ & $1,672.4$ & $1,693.5$ & $1,873.3$ & 2,184 \\
\hline Autónomas & 401.6 & 447.7 & 485.9 & 461.7 & 376 \\
\hline Banco Central & 191.4 & 240.9 & 237.5 & 165.4 & 160 \\
\hline \multicolumn{6}{|l|}{ IV. Sector público } \\
\hline Desembolsos & 315.9 & 566.1 & 975.2 & 477.8 & 613 \\
\hline Servicios & 292.3 & 388.2 & 843.4 & 565.2 & 549 \\
\hline Amortización & 192.4 & 285.6 & 738.6 & 463.4 & 439 \\
\hline Intereses & 99.9 & 102.6 & 104.8 & 101.9 & 111 \\
\hline Desembolso menos amortización & 123.5 & 280.5 & 236.6 & 14.5 & 174 \\
\hline \multicolumn{6}{|l|}{$V$. Indicadores de deuda } \\
\hline Saldo / PIB & $22.8 \%$ & $24.3 \%$ & $23.9 \%$ & $22.1 \%$ & $23.1 \%$ \\
\hline Intereses/Export. bienes & $6.0 \%$ & $5.7 \%$ & $4.3 \%$ & $4.1 \%$ & $4.4 \%$ \\
\hline Servicios/Export. bienes & $17.6 \%$ & $21.6 \%$ & $34.6 \%$ & $22.7 \%$ & $21.8 \%$ \\
\hline
\end{tabular}

Fuente: BCR. 1/ Cifras preliminares; 2/ No incluye deuda garantizada.

De esta manera tenemos que el escaso crecimiento económico observado en los últimos cuatro años, cuestiona seriamente el rumbo que lleva el país. Durante la primera mitad de la década de los noventa se lograron altas tasas de crecimiento. No sería aventurado asegurar que aquéllos fueron años de crecimiento "fácil", favorecidos por la firma de los acuerdos de paz; la ayuda extranjera para cumplir con los acuerdos de paz; la reactivación de los sectores productivos ante un mayor optimismo, y la expansión en la utilización de recursos productivos que habían permanecido ocio- 
sos por el conflicto, tales como la mano de obra, el capital y la tierra, aunado a un boom de consumo y del mercado de bienes raíces. Sin embargo, a partir de $1996 \mathrm{El}$ Salvador ha entrado en una tendencia al estancamiento, ya que con la limitación de recursos no se puede aumentar el crecimiento si éste no sc basa en incrementos en la productividad y la eliciencia. En tal sentido, los esfuerzos de todos los sectores y actores del país deben ser monumentales.

Adicionalmente al problema del escaso crecimiento, hay que agregar las enormes deficiencias sociales que existen en el modelo económico imperante. Si bien el análisis no ha sido exhaustivo en este campo con los datos aquí presentados, se evidencian altos niveles de desempleo, el estancamicnto por una década de los salarios mínimos reales -que es la moda estadística para la gran mayoría de los trabajadores-, el lento crecimiento de los salarios reales promedio y la concentración del ingreso —en que el 20 por ciento de las lamilias más pobres reciben apenas el 5.7 por ciento del ingreso-. Todo lo cual se traduce en cientos de miles de personas que viven en condiciones de pobreza y extrema pobreza.

En cste contexto encontramos que, a lo largo de los últimos cuatro años, el país no logra despegar para entrar en una etapa de desarrollo económico sostenido y sostenible. El agotamiento del crecimiento económico se ve reflejado en una caída del dinamismo en aquellos sectores que más han sustentado el crecimiento, como es el caso del sector industrial y las exportaciones de maquila. Esto se ve agravado con el hecho de que existe en el país una demanda agregada deprimida —en gran parte por el estancamiento de los salarios mínimos reales-, el cxiguo dinamismo de la inversión privada y la contracción en el crecimiento de las exportaciones. Adicionalmente, la política macrocconómica no ha sido capaz de crear un entorno favorable para la inversión, a pesar del éxito en el combate contra la inflación; y mucho menos ha logrado articular una política de desarrollo sectorial para la agricultura. Por la manera en que se ha "atado" el tipo de cambio, se esterilizan las entradas de divisas al Banco Central de Reserva, se aumenta el encaje legal en el último año y, por la tendencia al oligopolio en la industria bancaria, las tasas de interés reales han aumentado hasta alcanzar niveles tan altos, que dificultan la operación de las empresas y desestimulan la inversión tanto productiva como en vivienda. Agregado a este fenómeno se tiene una creciente mora bancaria y un incremento de los activos embargados de los bancos, reflejo de la deteriorada situación económica.

En conclusión, de acuerdo con lo esperado en los siguientes meses, no se visualiza un cambio sustancial en la evolución de la economía ni en la política económica; seguiremos postergando la eliminación de las graves deficiencias económicas y sociales del país. Para salir adelante, es necesario articular un nuevo eje de acumulación que le imprima dinamismo permanente a la economía. El eje de acumulación podría estar constituido por la maquila y por las exportaciones no tradicionales —especialmente este último, porque puede adquirir un carácter más diversificador y permanente-. en donde los productos agrícolas y agroindustriales puedan desempeñar una función importante. Pero esto debe estar condicionado a la creación de instituciones fuertes que promuevan la competencia - ley de competencia y antimonopolios-. los derechos de los trabajadores - seguridad social y protección al empleo- y los derechos de los consumidores - derechos del consumidor-, con el fin que se vaya creando un modelo de acumulación más humano. A nivel inmediato, el Estado debería asumir medidas de emergencia para mejorar las condiciones de aquellos que viven en extrema pobreza, sobre todo al hacer más eficiente el gasto público y la recaudación de impuestos, y al eliminar gastos innecesarios del presupuesto nacional para ponerlos al servicio del bienestar social. No estaría de más sugerir que aprendamos del ejemplo de Costa Rica, que hace varias décadas eliminó sus gastos militares y ubicó a la educación en primer plano. 